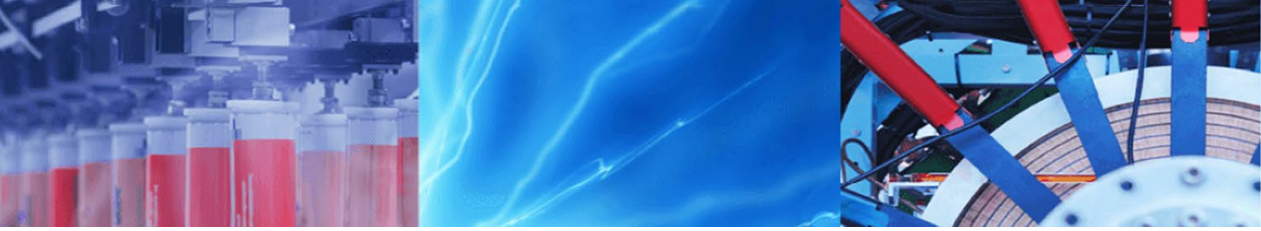

Research Article

\title{
Linear and nonlinear kinetic and isotherm adsorption models for arsenic removal by manganese ferrite nanoparticles
}

\author{
Jaime López-Luna' ${ }^{1}$ (D) Loida E. Ramírez-Montes ${ }^{1}$. Sergio Martinez-Vargas ${ }^{2}$ - Arturo I. Martínez ${ }^{3}$. \\ Oscar F. Mijangos-Ricardez ${ }^{1} \cdot$ María del Carmen A. González-Chávez ${ }^{4} \cdot$ Rogelio Carrillo-González $^{4}$. \\ Fernando A. Solís-Domínguez ${ }^{5} \cdot$ María del Carmen Cuevas-Díaz ${ }^{6} \cdot V^{2}$ irgilio Vázquez-Hipólito ${ }^{7}$
}

(c) Springer Nature Switzerland AG 2019

\begin{abstract}
In the present work, we analyzed the linear and nonlinear model suitabilities for adsorption data from aqueous As(III) removal by manganese ferrite nanoparticles (NPs). Hence, As(III) adsorption onto ferrite NPs was formerly analyzed by the intraparticle diffusion model (IPD). Then, adsorption kinetics was described by the pseudo-first-order (PFO), pseudosecond-order (PSO), and Elovich models, while equilibrium adsorption was fitted to the Freundlich and Langmuir isotherms. Linear and nonlinear kinetic and isotherm models were solved and compared. The nonlinear data fitting was applied through the Isqcurvefit user-defined function (Matlab ver. 7.10.0). The initial adsorption rate was influenced by intraparticle diffusion and surface or film diffusion from the arsenic bulk solution to ferrite NPs, according to the IPD model. Adsorption kinetics of As(III) on manganese ferrite NPs was better described by the PSO model, followed by the Elovich model and then the PFO model. Equilibrium adsorption data were only worthily described by the Freundlich isotherm model. While the PSO, Elovich and Freundlich linear models showed even better fit than the nonlinear models, determinant bias was depicted for the PFO and Langmuir linear models. Thus, to use nonlinear adsorption models is highly advisable, having the Matlab Isqcurvefit function been proven very useful to face such task.
\end{abstract}

Keywords As(III) adsorption $\cdot \mathrm{MnFe}_{2} \mathrm{O}_{4} \mathrm{NPs} \cdot \mathrm{IPD} \cdot \mathrm{PFO} \cdot \mathrm{PSO} \cdot$ Elovich · Freundlich · Langmuir

\section{Introduction}

Global water pollution has become a major environmental concern worsened by progressive incorporation of heavy metals and metalloids, such as chromium, cadmium, mercury, lead, and arsenic [1]. Chronic arsenic exposure from contaminated water and food could cause severe deleterious effects on worldwide health [2, 3]. The prevalent arsenic organic species in nature are the organoarsenicals and methylated forms, whereas the inorganic species comprise arsenite and arsenate $[2,4,5]$. Arsenic is discharged by industrial processes and used in agricultural applications, but water contamination is most often related to dissolution or leaching of solid-phase arsenic contained within the rocks, soil, and minerals into groundwater [6].

Electronic supplementary material The online version of this article (https://doi.org/10.1007/s42452-019-0977-3) contains supplementary material, which is available to authorized users.

$\bowtie$ Jaime López-Luna, jlol_24@hotmail.com; $\bowtie$ Virgilio Vázquez-Hipólito, virgilio@mixteco.utm.mx| ${ }^{1}$ Instituto de Estudios Ambientales, Universidad de la Sierra Juárez, 68725 Ixtlán de Juárez, Oaxaca, Mexico. ${ }^{2}$ Facultad de Ingeniería, Universidad Autónoma del Carmen, 24115 Ciudad del Carmen, Campeche, Mexico. ${ }^{3}$ Cinvestav-Saltillo Industrial, Zona Industrial, 25900 Ramos Arizpe, Coahuila, Mexico. ${ }^{4}$ Colegio de Postgraduados en Ciencias Agrícolas, Carr. México-Texcoco km 36.5, 56230 Montecillo, Estado de México, Mexico. ${ }^{5}$ Facultad de Ingeniería, Universidad Autónoma de Baja California, 21280 Mexicali, Baja California, Mexico. ${ }^{6}$ Facultad de Ciencias Químicas, Universidad Veracruzana, 96535 Coatzacoalcos, Veracruz, Mexico. ${ }^{7}$ Instituto de Física y Matemáticas, Universidad Tecnológica de la Mixteca, 69000 Huajuapan de León, Oaxaca, Mexico. 
$\mathrm{As}(\mathrm{III})$ and $\mathrm{As}(\mathrm{V})$ are the most common toxic forms of arsenic present in drinking water sources. But the major species in the reducing environment of groundwater is the more mobile and more toxic As(III) [6]. Thus, more than 100 million people from highly dense areas including Bangladesh, China, India, Pakistan, Taiwan, and Mexico are living at threat of arsenic contaminated groundwater [7]. Accordingly, adsorption is one of the most accepted methods for arsenic removal from water and it has been currently considered as an efficient and economical method for water treatment [8]. Last are statements supported by successful arsenic removal from water using iron oxide NPs such as magnetite [9-11], mixed magnetite/maghemite [12], hematite [13, 14], manganese/cobalt ferrite [15, 16], nickel ferrite [17], and magnetic composites $[6,18]$. Therein, efforts have been constantly done toward the functionalization of magnetic materials in order to obtain nanocomposites with an enhanced adsorption capacity of aqueous arsenic species [19-24]. Furthermore, as the mechanism of the adsorption process is not yet fully understood, adsorption studies using ferrite NPs are mainly focused in thermodynamics and the mechanisms of arsenic adsorption on the NPs surface, highlighting the redox reactions over the proposed surface complex formation $[2,11,25]$. Thus, the misleading use of linearized adsorption models may contribute to uncertainty, as the relationship between adsorption kinetics and thermodynamics parameters has not been completely clarified yet.

In fact, many attempts have been made over time to formulate general expressions describing kinetics of sorption on solid surfaces for liquid-solid phase sorption systems [26]. Hence, the behavior of initial adsorption has been analyzed based on the commonly known as the Weber and Morris equation [27] or intraparticle diffusion model (IPD) [28]. The pseudo-first-order (PFO) model, pseudo-second-order (PSO) and Elovich model have been the most applied chemisorptions models for studying kinetics of aqueous pollutants removal by using several adsorbents [26, 29-32]. Whereas Freundlich and Langmuir are still the most common used isotherm models for the analysis of adsorption systems at equilibrium [33-35]. The referred adsorption models can be easily solved by linearization, where the linear regression coefficient $\left(R^{2}\right)$ is commonly used as indicative of model fittingness. For most two parameter models, coefficient of determination for the linear regression giving an $R^{2}$ value closest to unity has been assumed to provide the best fit. Nonetheless, such transformations of nonlinear equations to linear forms implicitly alter their error structure and may also violate the error variance and normality assumptions of standard least squares [36]. Consequently, more recent investigations have shown that the nonlinear method is better than the linear method for fitting either the kinetics and isotherm models [37].

Nonlinear models had been commonly solved with algorithms based on the Levenberg-Marquardt or Gauss-Newton methods [36]. Parameters of kinetics or equilibrium adsorption models have been also obtained from nonlinear regression method by using software such as PSI-Plot program [9], Origin [37, 38], and Fig. P Software [39]. Nonlinear regression usually involves the minimization or maximization of error distribution between the experimental and predicted data, based on its convergence criteria [40]. However, the election of a specific kind of error can affect the model-derived parameters. Hence, this issue has been solved by normalization of the different errors and then selecting the parameters of the model whose error function accounts for the minimal sum of normalized errors [36].

In the present work, the initial behavior of As(III) adsorption onto manganese ferrite NPs was analyzed by the intraparticle diffusion model. For adsorption kinetics, the pseudo-first-order, pseudo-second-order, and Elovich models were employed, whereas the Freundlich and Langmuir isotherm models were used for equilibrium adsorption. Kinetic and isotherm models were fitted in their linear and nonlinear forms. The nonlinear data fitting was applied to the nonlinear models through the Isqcurvefit user-defined function (Matlab ver. 7.10.0). Linear and nonlinear models were compared, and discussion was focused on arsenic adsorption onto iron oxide NPs.

\section{Materials and methods}

Extensive experiments of $\mathrm{As}(\mathrm{III})$ and $\mathrm{As}(\mathrm{V})$ adsorption on manganese ferrite NPs were reported in [1]. For brevity, the present work was only focused on linear and nonlinear kinetic and isotherm models of As(III) adsorption onto manganese ferrite NPs.

\subsection{Synthesis and characterization of manganese ferrite NPs}

The manganese ferrite NPs used as adsorbent were synthesized by an adaptation of Massart's method [41]. Firstly, $2.0 \mathrm{mmol}$ of $\mathrm{MnSO}_{4} \cdot \mathrm{H}_{2} \mathrm{O}$ was dissolved in $2.5 \mathrm{~mL}$ of deionized water and $0.5 \mathrm{~mL}$ of $\mathrm{HCl} 1.0 \mathrm{~N}$. Then, $0.5 \mathrm{mmol}$ of $\mathrm{FeSO}_{4} \cdot 7 \mathrm{H}_{2} \mathrm{O}$ was dissolved in $2.5 \mathrm{~mL}$ of deionized water and $0.5 \mathrm{~mL}$ of $\mathrm{HCl} 1.0 \mathrm{~N}$. The solutions were mixed to add $4.0 \mathrm{mmol}$ of $\mathrm{Fe}\left(\mathrm{NO}_{3}\right)_{3} \cdot 9 \mathrm{H}_{2} \mathrm{O}$ dissolved in $2.5 \mathrm{~mL}$ of deionized water and $0.5 \mathrm{~mL}$ of $\mathrm{HCl} 1.0 \mathrm{~N}$. This mixture was vigorously stirred, and $100 \mathrm{~mL}$ of $\mathrm{NaOH} 1.5 \mathrm{M}$ was 
added dropwise. Afterward, the reaction mixture was thermally treated at $80^{\circ} \mathrm{C}$ under vigorous agitation for $90 \mathrm{~min}$. The black precipitate obtained was rinsed thrice with deionized water by soft magnetic decantation, to finally be dried at $45^{\circ} \mathrm{C}$.

The mean particle size and size distribution were determined by dynamic light scattering of a fresh sample suspended in acetone, by using a Microtrac Nanotrac 252 particle size analyzer (Microtrac, Inc., USA). Bulk NPs density was conventionally determined, and the total surface area of NPs per unit mass was calculated from the mean particle size. The $\mathrm{pH}$ of at the point of zero charge $\left(\mathrm{pH}_{\mathrm{PZC}}\right)$ of NPs was determined by the conventional $\mathrm{pH}$ drift method. X-ray diffraction (XRD) was conducted to evaluate the structural characteristics of the sample through a Philips diffractometer X'Pert with $\mathrm{Cu}(K a)$ radiation in a 2-theta range of $10^{\circ}-80^{\circ}$ was used (Cinvestav, Saltillo, México). The morphology and EDX elemental analysis of the samples was obtained by transmission electron microscopy (TEM) in an FEI 80-300 Schottkytype Microscope (CIQA, Saltillo, México), where conventional TEM images and diffraction patterns (SAED) of NPs were obtained. The magnetic properties were measured at room temperature ( $300 \mathrm{~K}$ ) in an AGM Micromag 2900 magnetometer. In addition, the atomic ratio of manganese and iron was determined by a Perkin-Elmer Optima 7000 DV ICP-OES Spectrometer.

\subsection{Adsorption experiment}

Sodium (meta) arsenite was used to obtain As(III) solutions $(2,5,10,20$, and $40 \mathrm{mg} / \mathrm{L})$ that were prepared in deionized water and adjusted at $\mathrm{pH} 2$ and 8 , respectively. For adsorption experiments, $0.4 \mathrm{~g} / \mathrm{L}$ of manganese ferrite NPs were placed in polyethylene bottles of $30 \mathrm{~mL}$ to add $10 \mathrm{~mL}$ of arsenic solution. The bottles were mechanically shaken at $250 \mathrm{rpm}$ and after $5,10,15,30,60,120$, and 240 min of contact time among NPs and the metalloid, the complete content of the bottles was decanted using a soft magnetic field and filtered through Whatman \#42 ashless filter paper. Arsenic determination was performed by ICP-OES. All experiments were conducted in duplicate at room temperature (293-295 K).

Arsenic adsorption over time $q_{t}(\mathrm{mg} / \mathrm{g})$ was calculated by the following equation

$q_{t}=\left(C_{0}-C_{t}\right) \frac{V}{m}$

where $C_{0}(\mathrm{mg} / \mathrm{L})$ is the initial arsenic solution concentration, $C_{t}(\mathrm{mg} / \mathrm{L})$ is the metalloid concentration after contact time, $V(\mathrm{~L})$ is the volume of the solution, and $m$ ) is the adsorbent weight.

\subsection{Adsorption, kinetic, and isotherm models}

The behavior of initial adsorption was analyzed based on the commonly known as the Weber and Morris equation [27] or intraparticle diffusion model (IPD) [28] shown in the linear Eq. 2 (Table 1). This model is usually applied in three forms: (a) First form is by getting a plot with a straight line that is forced to pass through the origin. (b) Second form is by a multi-linearity plot with two or three steps, involving the whole process. This way, the external surface adsorption or instantaneous adsorption occurs in the first step, and the second step is the gradual adsorption where intraparticle diffusion is controlled, and the third step is the final equilibrium where the solute moves slowly from larger pores to micropores causing a slow adsorption rate. (c) Third form is a straight line is obtained but does not necessarily pass through the origin; that is, there is an intercept. Intercept is proportional to the extent of the boundary layer thickness, the larger the intercept the greater the boundary layer effect [28]. Kinetics of arsenic adsorption was analyzed with the linear and nonlinear chemisorption models, namely pseudo-first-order model (PFO) [38], pseudo-second-order model (PSO) [42] and the Elovich model [43, 44], which equations are listed in Table 1. Lagergren's kinetics equation (PFO model) has been most widely used for describing the adsorption of liquid-solid systems based on solid capacity [31]. The PSO model has been successfully applied to the adsorption of metal ions, dyes, herbicides, oils, and organic substances from aqueous solutions [32]. The exponential Elovich equation has general application to chemisorption kinetics and has been used to describe the kinetics of heterogeneous exchange reactions [43]. As the sorption kinetics reached equilibrium, linear and nonlinear Langmuir and Freundlich isotherm models were applied, with the equations also listed in Table 1. Langmuir isotherm implies monolayer adsorption by energetically identical sites, while Freundlich isotherm describes heterogeneous surfaces and does not assume monolayer capacity [33].

\subsubsection{Analysis of linear and nonlinear models}

Linear regression has been one of the most viable tools defining the best-fitting relationship quantifying the distribution of adsorbates, mathematically analyzing the adsorption systems and verifying the consistency and theoretical assumptions of a specific model [34]. Hence, the accuracy of the fit of an adsorption model to experimental data is typically assessed based on the magnitude of the linear coefficient of determination, with $R^{2}$ values closest to unity being deemed to provide the best fit. Accordingly, adsorption, kinetic, and isotherm linear models were solved in Origin 6.0, where the constants of the 
Table 1 Integrated adsorption, kinetic and isotherm models

\begin{tabular}{|c|c|c|c|c|}
\hline & Equation & Plot & Constants & References \\
\hline \multicolumn{5}{|l|}{ Initial adsorption model } \\
\hline$q_{t}=k_{\mathrm{IPD}} t^{1 / 2}+C$ & (2) Linear & $q_{t}$ versus $t^{1 / 2}$ & $\begin{array}{l}k_{\mathrm{IPD}}\left(\mathrm{mg} / \mathrm{g} \mathrm{min}^{1 / 2}\right) \\
C(\mathrm{mg} / \mathrm{g})\end{array}$ & {$[28]$} \\
\hline \multicolumn{5}{|l|}{ Kinetic models } \\
\hline $\begin{array}{l}\text { Pseudo first order (PFO) } \\
\qquad \begin{array}{l}\ln \left(q_{\mathrm{e}}-q_{t}\right)=\ln q_{\mathrm{e}}-k_{1} t \\
q_{t}=\left(q_{\mathrm{e}}-e^{-k_{1} t}\right)\end{array}\end{array}$ & $\begin{array}{l}\text { (3) Linear } \\
\text { (4) Nonlinear }\end{array}$ & $\begin{array}{l}\ln \left(q_{\mathrm{e}}-q_{t}\right) \text { versus } t \\
q_{t} \text { versus } t\end{array}$ & $k_{1}\left(\min ^{-1}\right)$ & {$[38]$} \\
\hline \multicolumn{5}{|l|}{ Pseudo second order (PSO) } \\
\hline $\begin{aligned} \frac{t}{q_{t}} & =\frac{1}{k_{2} q_{\mathrm{e}}^{2}}+\frac{1}{q_{\mathrm{e}}} t \\
q_{t} & =\frac{k_{2} q_{\mathrm{e}}^{2} t}{1+k_{2} q_{\mathrm{e}} t}\end{aligned}$ & $\begin{array}{l}\text { (5) Linear } \\
\text { (6) Nonlinear }\end{array}$ & $\begin{array}{l}t / q_{t} \text { versus } t \\
q_{t} \text { versus } t\end{array}$ & $\begin{array}{l}k_{2}(\mathrm{~g} / \mathrm{mg} \min ) \\
k_{2} q_{\mathrm{e}}^{2} \text { or } h(\mathrm{mg} / \mathrm{g} \min )\end{array}$ & {$[42]$} \\
\hline \multicolumn{5}{|l|}{ Elovich } \\
\hline $\begin{array}{c}q_{t}=\frac{1}{\beta} \ln \alpha \beta+\frac{1}{\beta} \ln t \\
q_{t}=\frac{1}{\beta} \ln (1+\alpha \beta t) \\
\text { Isotherm models }\end{array}$ & $\begin{array}{l}\text { (7) Linear } \\
\text { (8) Nonlinear }\end{array}$ & $\begin{array}{l}q_{t} \text { versus } \ln t \\
q_{t} \text { versus } t\end{array}$ & $\begin{array}{l}\alpha(\mathrm{mg} / \mathrm{g} \min ) \\
\beta(\mathrm{g} / \mathrm{mg})\end{array}$ & {$[43,44]$} \\
\hline $\begin{array}{l}\text { Freundlich } \\
\qquad \log q_{\mathrm{e}}=b_{\mathrm{F}} \log C_{\mathrm{e}}+\log K_{\mathrm{F}} \\
q_{\mathrm{e}}=K_{\mathrm{F}} C_{\mathrm{e}}^{b_{\mathrm{F}}}\end{array}$ & $\begin{array}{l}\text { (9) Linear } \\
\text { (10) Nonlinear }\end{array}$ & $\begin{array}{l}\log q_{\mathrm{e}} \text { versus } \log C_{\mathrm{e}} \\
q_{\mathrm{e}} \text { versus } C_{\mathrm{e}}\end{array}$ & $\begin{array}{l}K_{\mathrm{F}}(\mathrm{L} / \mathrm{g}) \\
b_{\mathrm{F}} \text { (unitless) }\end{array}$ & [33] \\
\hline \multicolumn{5}{|l|}{ Langmuir } \\
\hline $\begin{array}{l}\frac{1}{q_{\mathrm{e}}}=\frac{1}{K_{\mathrm{L}} C_{\mathrm{e}}}+\frac{a_{\mathrm{L}}}{K_{\mathrm{L}}} \\
q_{\mathrm{e}}=\frac{K_{\mathrm{L}} C_{\mathrm{e}}}{1+a_{\mathrm{L}} C_{\mathrm{e}}}\end{array}$ & $\begin{array}{l}\text { (11) Linear } \\
\text { (12) Nonlinear }\end{array}$ & $\begin{array}{l}1 / q_{\mathrm{e}} \text { versus } 1 / C_{\mathrm{e}} \\
q_{\mathrm{e}} \text { versus } C_{\mathrm{e}}\end{array}$ & $\begin{array}{l}K_{\mathrm{L}}(\mathrm{L} / \mathrm{g}) \\
a_{\mathrm{L}}(\mathrm{L} / \mathrm{mg}) \\
\frac{K_{\mathrm{L}}}{a_{\mathrm{L}}}(\mathrm{mg} / \mathrm{g})\end{array}$ & [33] \\
\hline
\end{tabular}

$q_{t}$ is adsorption over time $(\mathrm{mg} / \mathrm{g}), q_{\mathrm{e}}$ is adsorption at equilibrium $(\mathrm{mg} / \mathrm{g}), k_{\mathrm{IPD}}$ is the intraparticle diffusion rate constant $\left(\mathrm{mg} / \mathrm{g} \mathrm{min}{ }^{1 / 2}\right), C$ is a constant of any experiment $(\mathrm{mg} / \mathrm{g}), k_{1}$ is the PFO rate constant $\left(\mathrm{min}^{-1}\right), k_{2}$ is the PSO rate constant $(\mathrm{g} / \mathrm{mg} \mathrm{min}), k_{2} q_{\mathrm{e}}^{2}$ or $h$ is the initial PSO adsorption rate ( $\left.\mathrm{mg} / \mathrm{g} \mathrm{min}\right)$, $\alpha$ is the Elovich initial adsorption rate $(\mathrm{mg} / \mathrm{g} \mathrm{min}), \beta(\mathrm{g} / \mathrm{mg})$ desorption constant, $C_{\mathrm{e}}$ is the aqueous concentration at equilibrium $(\mathrm{mg} / \mathrm{L}), K_{\mathrm{F}}$ reflects the adsorbent capacity $(\mathrm{L} / \mathrm{g}), b_{\mathrm{F}}$ is the heterogeneity factor (unitless) ranging from 0 to $1, K_{\mathrm{L}}$ reflects the solute adsorptivity $(\mathrm{L} / \mathrm{g}), a_{\mathrm{L}}(\mathrm{L} / \mathrm{mg})$ is related to the energy of adsorption and $K_{\mathrm{L}} / a_{\mathrm{L}}$ is defined as the monolayer adsorbent capacity models were calculated from the slope and the intercept of straight lines, using the linear regression coefficient $\left(R^{2}\right)$ as model fit suitability.

Regarding isotherm models, transformations of nonlinear equations to linear forms may produce bias like poor linearity despite high linear regression coefficients, or the tendency of the Freundlich model to better fit data at low experimental concentrations and the Langmuir model to better fit data at higher experimental concentrations [36]. Thus, nonlinear optimization is a mathematically rigorous method to determine the parameters of the adsorption model using the original form of the equation. Nonetheless, the selection of an error function is required for assessment of fit accuracy of a model to experimental adsorption data [45]. Unfortunately, the algorithms are commonly solved individually with the different sources of error, displaying differences in the model parameters values, making it difficult to establish the criteria for the selection of those values [1]. Hence, the different kinds of errors have been normalized and then selecting the parameters of the model whose error function accounted for the minimal sum of normalized errors, implying the best overall fit [36].

Since in the nonlinear least square regression method the selection of a specific error function can affect the parameters derived and the normalization of different sources of error is time demanding, the nonlinear curve fitting (data fitting) was applied to the nonlinear models through the Isqcurvefit user-defined function, until resnorm minimization was achieved (Matlab ver. 7.10.0. Math Works Inc. Release R2009a, Perpetual License Number 581616, Universidad Tecnológica de la Mixteca, Oaxaca, México). Clearing out that Isqcurvefit requires the user-defined function to compute the vector value function, rather than compute the sum of squares. Although the criterion for model fittingness was resnorm minimization, several error functions were included in the algorithms. These functions are namely the Sum of 
the Square of the Errors (ERRSQ), Composite Fractional Error Function (HYBRD), Derivative of Marquardt's Percent Standard Deviation (MPSD), Average Relative Error (ARE), and the Sum of the Absolute Errors (EABS) [36]. The parameters of the models were the same through different sources of error. Because of being dimensionless, ARE and MPSD were the most representative error functions, but only the last one is presented for brevity. (Nonlinear Matlab algorithms are available in the Supplementary data section). Additionally, Chi-square $\left(\chi^{2}\right)$ was used as fittingness test by measuring the difference between experimental and model-calculated equilibrium adsorption data:

$\chi^{2}=\sum_{i=1}^{n} \frac{\left(q_{\mathrm{e}}, \exp -q_{\mathrm{e}^{\prime}} \text { cal }\right)^{2}}{q_{\mathrm{e}}, \mathrm{cal}}$

where $n=5$ corresponded to the 2, 5, 10, 20, and $40 \mathrm{mg} / \mathrm{L} \mathrm{As}(\mathrm{III})$ nominal concentrations. Hence, the
Chi-square tabular value at 0.05 level with $(n-1)$ degrees of freedom $=9.488$.

Table 2 shows the experimental means of arsenic adsorption data that was used to fit the linear and nonlinear adsorption models.

\section{Results and discussion}

\subsection{Characterization of manganese ferrite NPs}

The XRD pattern (Fig. 1a) shows the main peaks at $2 \theta=29.82^{\circ}, 35.11^{\circ}, 42.75^{\circ}, 52.91^{\circ}, 56.28^{\circ}$, and $61.88^{\circ}$ attributed, respectively, to the (220), (311), (400), (422), (511), and (440) crystallographic planes of the cubic spinel structure of the manganese ferrite $\mathrm{MnFe}_{2} \mathrm{O}_{4}$ (JCPDS Card No. 74-2403). Additionally, a lattice parameter of $a=8.4941 \AA$ was obtained by Rietveld refinement analysis and crystallite size of $35 \mathrm{~nm}$ was calculated by the Debye-Scherrer equation. TEM image of the sample shows agglomerates

Table 2 Arsenic adsorption onto manganese ferrite NPs

\begin{tabular}{|c|c|c|c|c|c|}
\hline Time (min) & $\begin{array}{l}2 \mathrm{mg} / \mathrm{L} \\
q_{t}(\mathrm{mg} / \mathrm{g})\end{array}$ & $\begin{array}{l}5 \mathrm{mg} / \mathrm{L} \\
q_{t}(\mathrm{mg} / \mathrm{g})\end{array}$ & $\begin{array}{l}10 \mathrm{mg} / \mathrm{L} \\
q_{t}(\mathrm{mg} / \mathrm{g})\end{array}$ & $\begin{array}{l}20 \mathrm{mg} / \mathrm{L} \\
q_{t}(\mathrm{mg} / \mathrm{g})\end{array}$ & $\begin{array}{l}40 \mathrm{mg} / \mathrm{L} \\
q_{t}(\mathrm{mg} / \mathrm{g})\end{array}$ \\
\hline \multicolumn{6}{|l|}{$A s(I I I), p H 2$} \\
\hline 5 & $3.82 \pm 0.081$ & $7.91 \pm 0.072$ & $13.61 \pm 0.161$ & $22.10 \pm 0.212$ & $42.48 \pm 1.432$ \\
\hline 10 & $4.60 \pm 0.083$ & $9.00 \pm 0.067$ & $14.47 \pm 0.049$ & $23.48 \pm 0.106$ & $42.63 \pm 1.732$ \\
\hline 15 & $4.95 \pm 0.072$ & $9.15 \pm 0.028$ & $14.98 \pm 0.113$ & $25.73 \pm 0.194$ & $43.28 \pm 0.866$ \\
\hline 30 & $5.25 \pm 0.083$ & $10.43 \pm 0.027$ & $17.19 \pm 0.058$ & $26.08 \pm 0.124$ & $43.55 \pm 1.397$ \\
\hline 60 & $5.29 \pm 0.081$ & $11.83 \pm 0.042$ & $18.07 \pm 0.194$ & $27.50 \pm 0.018$ & $44.80 \pm 1.344$ \\
\hline 120 & $5.35 \pm 0.080$ & $12.53 \pm 0.025$ & $19.21 \pm 0.216$ & $29.30 \pm 0.803$ & $46.90 \pm 1.450$ \\
\hline 180 & $5.38 \pm 0.076$ & $12.80 \pm 0.065$ & $17.88 \pm 0.156$ & $29.15 \pm 0.035$ & $49.05 \pm 0.194$ \\
\hline 240 & $5.39 \pm 0.076$ & $12.85 \pm 0.044$ & $20.54 \pm 0.069$ & $32.05 \pm 0.080$ & $49.53 \pm 0.227$ \\
\hline \multicolumn{6}{|l|}{$A s(I I I), p H 8$} \\
\hline 5 & $2.44 \pm 0.290$ & $4.31 \pm 0.133$ & $7.68 \pm 0.064$ & $11.88 \pm 0.177$ & $16.43 \pm 0.619$ \\
\hline 10 & $2.79 \pm 0.255$ & $4.76 \pm 0.060$ & $8.08 \pm 0.180$ & $13.50 \pm 0.636$ & $20.20 \pm 0.053$ \\
\hline 15 & $2.91 \pm 0.134$ & $4.35 \pm 0.080$ & $8.22 \pm 0.095$ & $14.23 \pm 0.344$ & $21.33 \pm 0.955$ \\
\hline 30 & $3.28 \pm 0.071$ & $6.27 \pm 0.042$ & $8.35 \pm 0.136$ & $17.58 \pm 0.212$ & $27.25 \pm 4.349$ \\
\hline 60 & $2.63 \pm 1.266$ & $6.64 \pm 0.074$ & $9.33 \pm 0.148$ & $19.40 \pm 0.092$ & $27.35 \pm 0.460$ \\
\hline 120 & $3.66 \pm 0.442$ & $7.03 \pm 0.057$ & $10.30 \pm 0.228$ & $20.14 \pm 0.458$ & $30.63 \pm 0.318$ \\
\hline 180 & $3.93 \pm 0.143$ & $7.51 \pm 0.016$ & $11.86 \pm 0.106$ & $20.99 \pm 0.064$ & $32.93 \pm 0.831$ \\
\hline 240 & $3.93 \pm 0.175$ & $7.80 \pm 0.062$ & $12.03 \pm 0.166$ & $21.36 \pm 0.076$ & $32.98 \pm 0.194$ \\
\hline $\mathrm{As}(\mathrm{III}), \mathrm{pH} 2$ (mg/L) & $C_{e}(\mathrm{mg} / \mathrm{L})$ & $q_{\mathrm{e}}(\mathrm{mg} / \mathrm{g})$ & $\mathrm{As}(\mathrm{III}), \mathrm{pH} 8$ (mg/L) & $C_{e}(\mathrm{mg} / \mathrm{L})$ & $q_{\mathrm{e}}(\mathrm{mg} / \mathrm{g})$ \\
\hline \multicolumn{6}{|c|}{ Adsorption at equilibrium } \\
\hline 2 & $0.003 \pm 0.000$ & $5.39 \pm 0.076$ & 2 & $0.25 \pm 0.052$ & $3.93 \pm 0.175$ \\
\hline 5 & $0.14 \pm 0.004$ & $12.85 \pm 0.044$ & 5 & $1.11 \pm 0.057$ & $7.80 \pm 0.062$ \\
\hline 10 & $2.52 \pm 0.029$ & $20.54 \pm 0.069$ & 10 & $3.58 \pm 0.064$ & $12.03 \pm 0.166$ \\
\hline 20 & $8.93 \pm 0.011$ & $32.05 \pm 0.080$ & 20 & $8.80 \pm 0.144$ & $21.36 \pm 0.076$ \\
\hline 40 & $24.76 \pm 0.417$ & $49.53 \pm 0.227$ & 40 & $20.23 \pm 0.120$ & $32.98 \pm 0.194$ \\
\hline
\end{tabular}

Results are means \pm standard deviation of two replicates, $q_{t}$ is adsorption over time, $C_{\mathrm{e}}$ and $q_{\mathrm{e}}$ represent aqueous arsenic concentration and arsenic adsorption at equilibrium (240 $\mathrm{min})$, respectively 

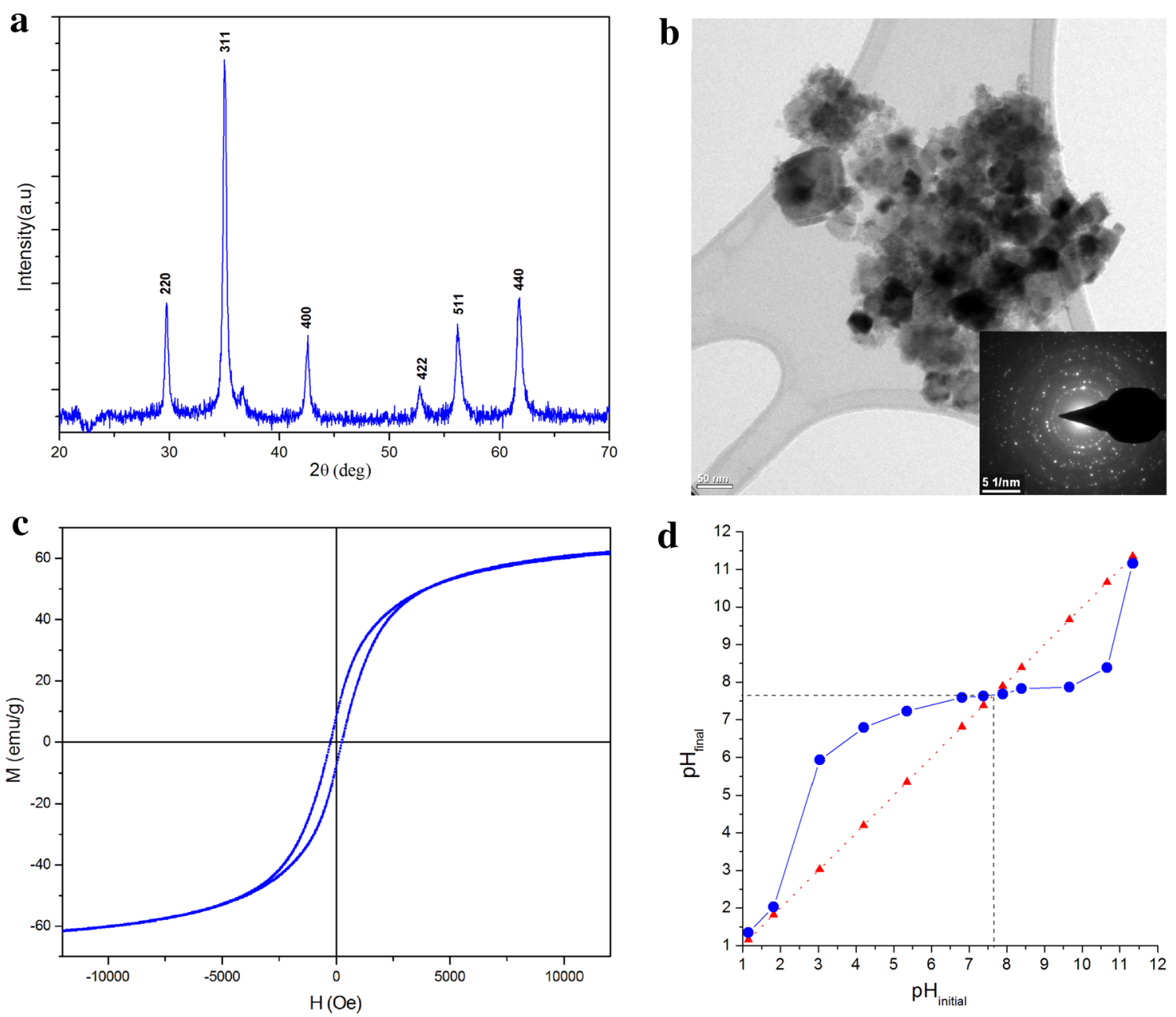

Fig. 1 Manganese ferrite NPs characterization: a X-ray diffraction patterns of manganese ferrite NPs, b TEM micrograph showing manganese ferrite NPs and the SAED pattern of NPS distribution, $c$

of round-shaped NPs within mean size of $\sim 2-6 \mathrm{~nm}$ and agglomerates of cubic particles no larger than $30-45 \mathrm{~nm}$ (Fig. 1b). The dynamic light scattering measurements of fresh NPs suspended in acetone showed a mean particle of $2.35 \mathrm{~nm}$, which are smaller than those measured by TEM. According to the EDX and ICP-OES elemental analyses, the atomic Mn content of NPs was $31 \%$ and $29.36 \%$, respectively. The Mn atomic \% in the ferrite NPs did not correspond to the $\mathrm{Mn}$ atomic \% in the starting solution, as in ternary systems the coprecipitation process become complex, attributed to differences in the solubility product constant of each component [1]. Nonetheless, the XRD pattern found NPs indexed to spinel structure of $\mathrm{MnFe}_{2} \mathrm{O}_{4}$. This ferrimagnetic material owns saturation magnetization $\left(M_{\mathrm{s}}\right)$ of $60.1 \mathrm{emu} / \mathrm{g}$, coercivity $(\mathrm{Hc})$ of $220 \mathrm{Oe}$, and remanent magnetization $\left(M_{\mathrm{r}}\right) 5.6 \mathrm{emu} / \mathrm{g}$ (Fig. 1c). The point of zero charge (PZC) of ferrite NPs was localized at pH 7.7 (Fig. 1d). NPs density was $5.22 \mathrm{~g} / \mathrm{cm}^{3}$ and surface area $81.09 \mathrm{~m}^{2} / \mathrm{g}$. hysteresis curve with specific magnetization for manganese ferrite $\mathrm{NPs}, \mathbf{d}$ point of zero charge $\left(\mathrm{pH}_{\mathrm{PZC}}\right)$ of manganese ferrite NPs

\subsection{As(III) adsorption on manganese ferrite NPs}

As a general trend, the increase in arsenic adsorption with increasing As(III) nominal concentrations (Table 2) corresponded to arsenic removal diminution. For lower As(III) nominal concentrations (2-10 mg/L), arsenic adsorption onto manganese ferrite NPs occurred rapidly, starting equilibrium conditions by $30 \mathrm{~min}$. Meanwhile, for the highest As(III) nominal concentrations equilibrium was delayed until 240 min of contact time between NPs and arsenic solutions. Initial fast adsorption of As(III) might be related to the fine NPs favoring its diffusion onto the active sites of manganese ferrite NPs surface from bulk arsenic solution, and the following slow adsorption rate could be dominantly controlled by intraparticle diffusion [2]. Last findings explained ahead through the intraparticle diffusion model. 
Unlike $\mathrm{pH} 8, \mathrm{As}$ (III) was better attracted to manganese ferrite NPs at $\mathrm{pH} 2$, depicting enhanced NPs adsorption capacity. Arsenic speciation in water is strongly affected by $\mathrm{pH}$ and $\mathrm{pE}$, being $\mathrm{H}_{3} \mathrm{AsO}_{3}^{0}$ and $\mathrm{HAsO}_{3}^{-2}$ the dominant arsenite species at low and high $\mathrm{pH}$, respectively [46]. Thus, in the present work $\mathrm{As}$ (III) adsorption onto manganese ferrite NPs was discouraged by increasing the $\mathrm{pH}$ of arsenic solutions above the point of zero charge $\left(\mathrm{pH}_{\mathrm{PZC}}=7.7\right)$. Therein, in alkaline $\mathrm{pH}$ the surface hydroxyl groups get deprotonated and negatively charged, thus causing desorption of negatively charged arsenic species [47]. In contrast to our results, the effect of $\mathrm{pH}$ (3-10) on As(III) adsorption onto $\mathrm{MnFe}_{2} \mathrm{O}_{4} \mathrm{NPs}$ was hardly observed as As(III) existed predominantly as $\mathrm{H}_{3} \mathrm{AsO}_{3}^{0}$ [15]. Arsenic adsorption on $\mathrm{MnFe}_{2} \mathrm{O}_{4}$ nanoadsorbent was also found almost independent of $\mathrm{pH}$ from 2 to 6 , whereas the $\mathrm{pH}$ dependence for $\mathrm{As}$ (III) adsorption onto $\mathrm{Fe}_{3} \mathrm{O}_{4}$ suggested that besides sorption, redox reaction mechanisms may be involved binding arsenic and different mineral phases [25]. Accordingly, the $\mathrm{pH}$ of the solution also affects the chemistry of both the mineral phase and the behavior of the arsenic solution, as the $\mathrm{MnFe}_{2} \mathrm{O}_{4}$ nanophase released about $2 \mathrm{mg} / \mathrm{L}$ of $\mathrm{Fe}$ and $40 \mathrm{mg} / \mathrm{L}$ of $\mathrm{Mn}$ in the presence of $\mathrm{As}$ (III) at $\mathrm{pH} 2$ [25]. Nonetheless, although in the present work dissolved ions released from NPs was not actually determined, model fittingness would be expected to be implied by the whole experimental parameters.

\subsection{Intraparticle diffusion (IPD) model}

The intraparticle diffusion model (IPD) fit for arsenic adsorption onto manganese ferrite NPs is shown in Fig. 2. Two straight lines not intercepting the origin were observed in both $\mathrm{pH}$ tested. The first straight line ranged from 5 to $30 \mathrm{~min}\left(2.24-5.48 \mathrm{~min}^{1 / 2}\right)$ of contact time among arsenic solutions and NPs, and the second one from 30 to $240 \mathrm{~min}\left(5.48-15.49 \mathrm{~min}^{1 / 2}\right)$. The deviation of straight lines from the origin can be attributed to the difference in the rate of mass transfer in the initial and final stages of adsorption [48]. Accordingly, in the present work initial stages of adsorption could have been implied by polydispersity of mean NPs size revealed by NPs characterization and the tendency of dry ferrite NPs to be more strongly agglomerated because of their magnetic properties. Thus intraparticle diffusion was assumed as not the only ratelimiting step [42]. In agreement, our results indicated a rapid first adsorption stage with surface or film diffusion from the arsenic bulk solution to ferrite NPs, where the rates $\left(k_{\mathrm{IPD} 1}\right)$ and solute boundary layers thickness $\left(C_{1}\right)$ increased with increasing arsenic nominal concentrations (Table 3). In contrast, in the second stage intraparticle or pore diffusion implied the main course of the adsorption process showing slower rates $\left(k_{\mathrm{IPD} 2}\right)$.

Indeed, intraparticle diffusion is responsible to consume more time due to the very slow diffusion of the adsorbates from the surface film into the micropores, which are the least accessible sites of adsorption [48]. The intraparticle diffusion stage was accompanied by an important increase in the boundary layer thickness $\left(C_{2}\right)$, whose values were below adsorption at equilibrium $\left(q_{\mathrm{e}}\right)$, so that a third equilibrium stage was actually not observed. Conversely, arsenite adsorption on a pine cone-magnetite composite presented a first stage indicating bulk diffusion with a straight line intercepting the origin, followed by a linear section which represents intraparticle diffusion and lastly a plateau section representing equilibrium [18]. In summary and in agreement with our findings, the adsorption mechanism is determined by
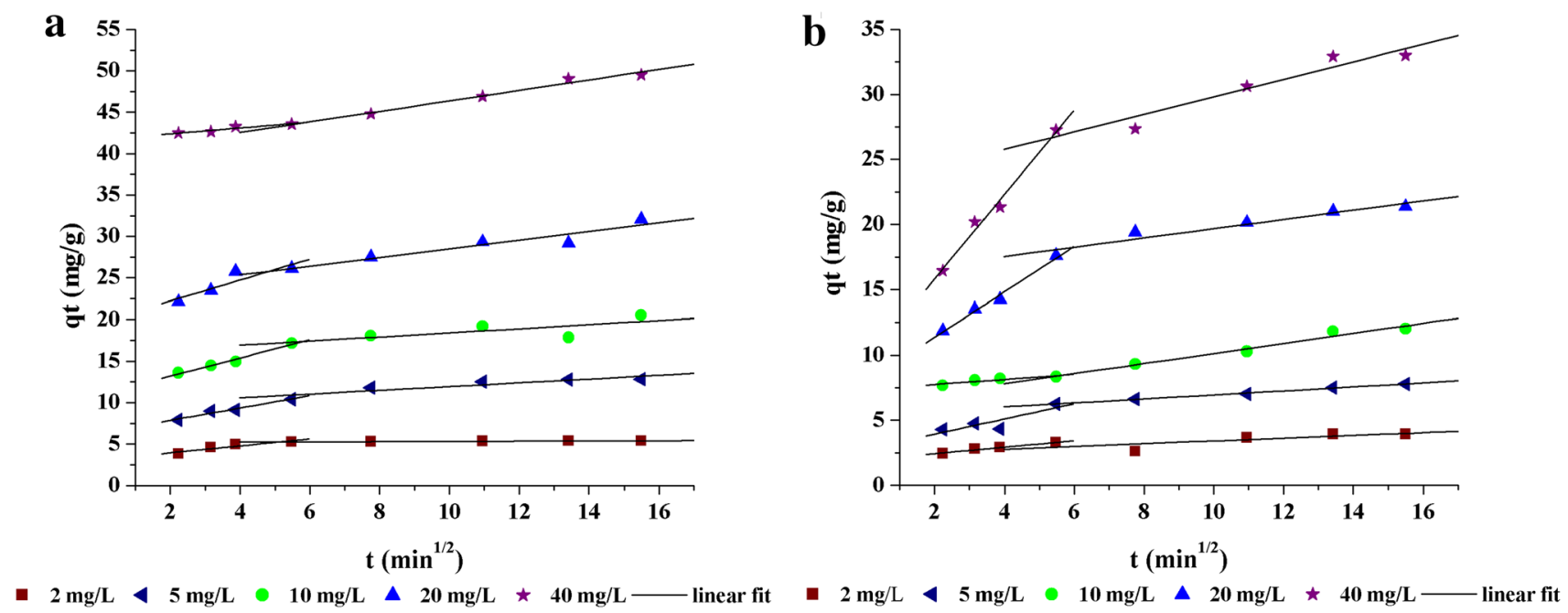

Fig. 2 Intraparticle diffusion (IPD) model of As(III) adsorption onto manganese ferrite NPs, conducted at a pH 2 and $\mathbf{b}$ pH 8 
Table 3 Parameters of the intraparticle diffusion (IPD) model

\begin{tabular}{|c|c|c|c|c|c|c|}
\hline & $k_{\mathrm{IPD} 1}\left(\mathrm{mg} / \mathrm{g} \mathrm{min} \mathrm{min}^{1 / 2}\right)$ & $C_{1}(\mathrm{mg} / \mathrm{g})$ & $R^{2}$ & $k_{\mathrm{IPD} 2}\left(\mathrm{mg} / \mathrm{g} \min ^{1 / 2}\right)$ & $C_{2}(\mathrm{mg} / \mathrm{g})$ & $R^{2}$ \\
\hline \multicolumn{7}{|c|}{$A s(I I I), p H 2(m g / L)$} \\
\hline 2 & 0.42 & 3.11 & 0.87 & 0.01 & 5.18 & 0.97 \\
\hline 5 & 0.74 & 6.39 & 0.98 & 0.23 & 9.67 & 0.85 \\
\hline 10 & 1.11 & 10.99 & 0.97 & 0.25 & 15.95 & 0.59 \\
\hline 20 & 1.26 & 19.71 & 0.83 & 0.52 & 23.26 & 0.91 \\
\hline 40 & 0.35 & 41.68 & 0.89 & 0.63 & 40.03 & 0.98 \\
\hline \multicolumn{7}{|c|}{$A s(I I I), p H 8(m g / L)$} \\
\hline 2 & 0.25 & 1.93 & 0.98 & 0.11 & 2.37 & 0.61 \\
\hline 5 & 0.58 & 2.77 & 0.76 & 0.15 & 5.43 & 1.00 \\
\hline 10 & 0.19 & 7.37 & 0.83 & 0.39 & 6.28 & 0.97 \\
\hline 20 & 1.74 & 7.87 & 0.98 & 0.36 & 16.12 & 0.94 \\
\hline 40 & 3.25 & 9.29 & 0.98 & 0.67 & 23.08 & 0.94 \\
\hline
\end{tabular}

three consecutive steps, namely 1.-external or film mass transfer of solute molecules from the solution bulk to the sorbent particle surface, succeeded by 2.--diffusion within the particle internal structure to the sorption sites where 3.- the immeasurable rapid uptake occurs, so that film mass transfer and intraparticle diffusion remain the rate determining steps [33].

\subsection{Linear and nonlinear kinetic models}

\subsubsection{Pseudo-first-order (PFO) model}

The pseudo-first-order kinetic model (PFO) assumes that the rate of change of solute uptake with time is directly proportional to the difference in equilibrium concentration and the amount of solute adsorbed with time [49]. In this sense, the PFO model was apparently inadequate to describe the kinetic behavior of arsenic adsorption onto manganese ferrite NPs, at least in its linear form (Fig. 3a, b; Table 4). When experimental data was plotted, linear trend was not observed for the whole arsenic nominal concentrations, despite suitable linear regression coefficients $\left(R^{2}\right)$. Likewise, poor linearity was perceived for the PFO model describing arsenate kinetics on copper ferrite [50] and arsenite kinetics on cobalt ferrite NPs aggregated schwertmannite [49], regardless of higher linear regression coefficients. Moreover, in the current work logarithmic undetermined values prevented a better fit of the PFO linear model. Thus, for both pHs tested the PFO adsorption rate constants $\left(k_{1}\right)$ were negative and of a small order of magnitude, maybe suggesting deprived affinity or repulsion between arsenic solutions and manganese ferrite NPs. For similar findings, the PFO model was discarded for adsorption kinetics of $\mathrm{Cd}(\mathrm{II})$ and $\mathrm{Cr}(\mathrm{VI})$ onto citrate-coated magnetite NPs [51].

With the PFO nonlinear model, the equilibrium sorption capacity $\left(q_{\mathrm{e}}\right)$ can be calculated directly from the course of adsorption over time; an important disadvantage for the PFO linear model to be applied is that such adsorption capacity should be previously experimentally determined. However, in many cases $q_{\mathrm{e}}$ is unknown and as chemisorption tends to become immeasurably slow, the amount sorbed is still significantly smaller than the equilibrium amount [26]. Accordingly, in the present work the calculated adsorption at equilibrium $\left(q_{\mathrm{e}}\right.$, cal) resulted deeply underestimated when compared to the experimental equilibrium adsorption capacity $\left(q_{\mathrm{e}}, \exp \right)$, thus greatly exceeding the Chi-square tabular value (9.488). In agreement with our results and despite higher linear regression coefficients, equilibrium adsorption capacity resulted also acutely underestimated when applying the PFO linear model to the adsorption kinetics of arsenic onto aluminum-doped nano-manganese copper ferrite [52] $\mathrm{Co}^{2+}$ ions on nano-magnesso ferrite [53] and As(III) onto humic acid grafted magnetite NPs [6].

From aqueous ions adsorption on organic zeolites where the PFO linear model fitted data properly, it was proposed that if the film diffusion is rate controlling the slope of the plots of Eq. 3 will vary inversely with the particle size, the film thickness, and with the distribution coefficient, $k$; but if the sorption rate controlling step is chemical exchange, the slope will be independent of particle diameter and flow rate and will depend only on the concentration of the sorbate in solution and the temperature [26, 54]. Hence, the mechanism of As(III) [55] and $\mathrm{As}(\mathrm{V})[56]$ sorption on hematite was suggested to be chemically rate controlling, as the rate constant inversely decreased depending on temperature [26]. Adsorption rate from As(III) adsorption kinetics on nickel ferrite was also found dependent on temperature, but it increased proportionally with temperature [17]. However, in adsorption kinetics of cobalt ions onto nano-magnesso ferrite conducted at $298 \mathrm{~K}$, adsorption rates were independent of initial solute concentrations [53]. Accordingly, the PFO 


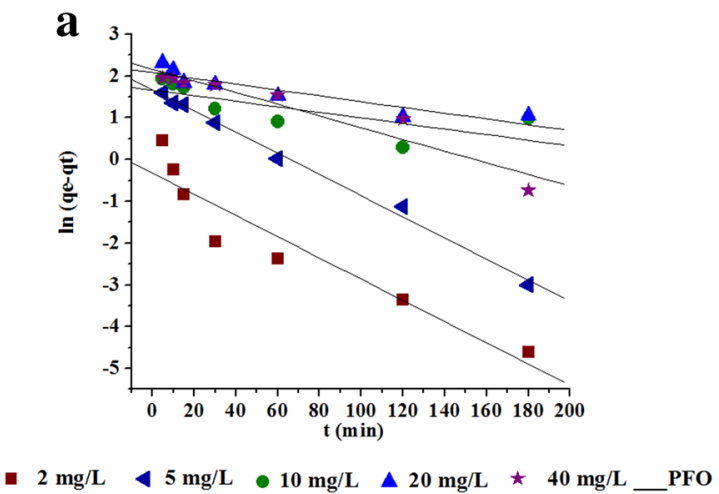

c

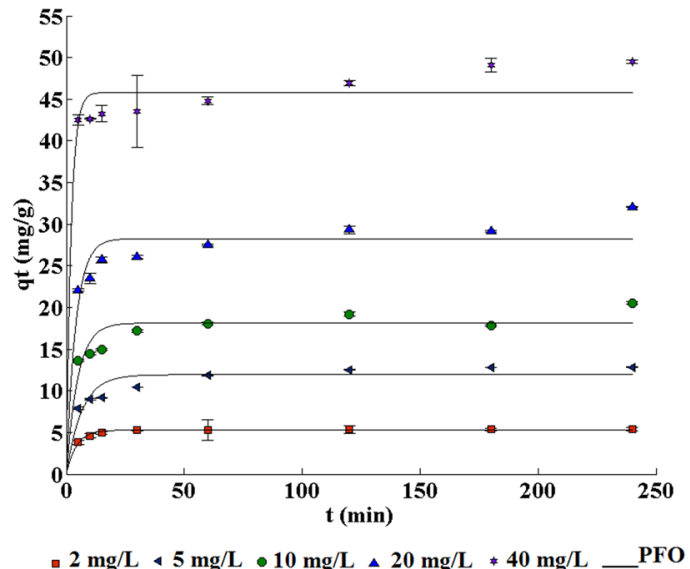

Fig. 3 Linear and nonlinear fit of the pseudo-first-order (PFO) kinetic model of $\mathrm{As}$ (III) adsorption onto manganese ferrite NPs $\mathbf{a}, \mathbf{b}$ PFO linearized model of adsorption kinetics conducted at $\mathrm{pH} 2$ and

linear model did not fit the present experimental data, but the rate constants from the nonlinear model at room temperature were also found independent of arsenic initial concentrations. Additionally, as demonstrated by Azizian's approaches, $k_{1}$ is not the intrinsic adsorption rate constant broadly reported in the literature, but a combination of adsorption $\left(k_{\mathrm{a}}\right)$ and desorption $\left(k_{\mathrm{d}}\right)$ rate constants that can be obtained from the slope and the intercept of a straight line by plotting $k_{1}$ versus solute initial concentrations; then, the equilibrium constant $K=k_{\mathrm{a}} / k_{\mathrm{d}}$ [30]. Nonetheless, in the present work such constants could not be calculated as a clear pattern was not observed among arsenic initial concentrations and $k_{1}$ rate constants. Maybe higher initial arsenic concentrations might fit both the linear and the nonlinear PFO models since it has been observed that sorption kinetics of high initial solute concentrations better fit the PFO model, whereas not too high initial solute concentrations better fit the PSO model [30]. Hence, additional experiments (higher arsenic concentrations, adsorption over a gradient of temperature, different adsorbent
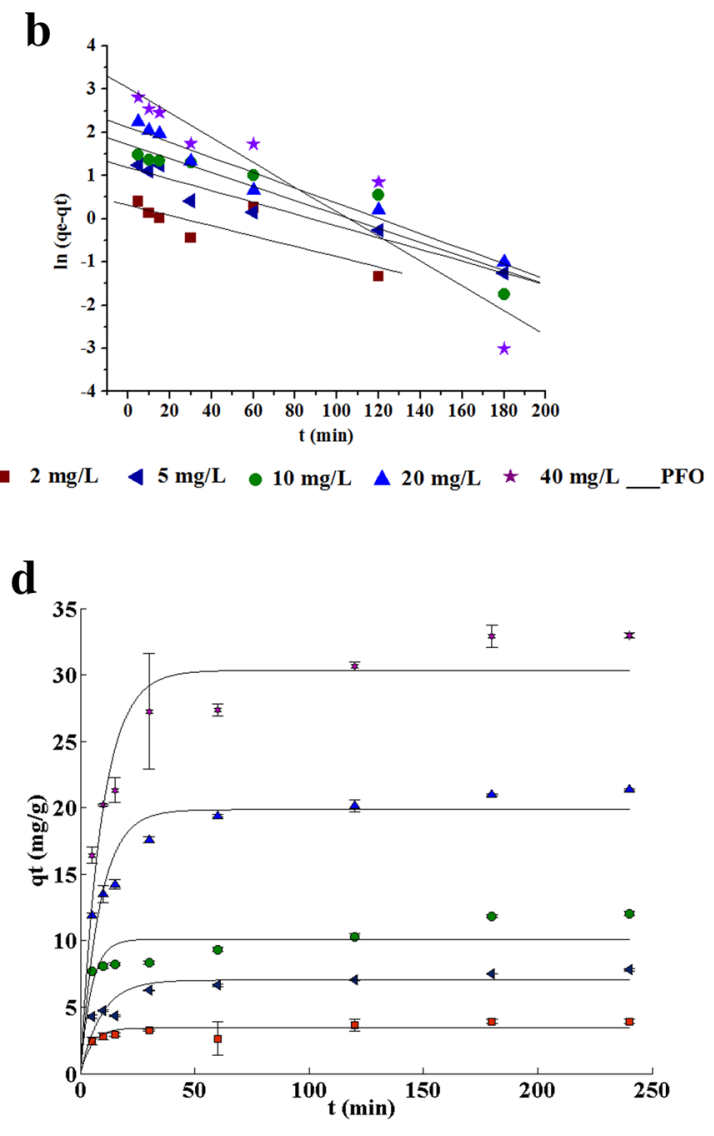

\2 mg/L $45 \mathrm{mg} / \mathrm{L} \bullet 10 \mathrm{mg} / \mathrm{L} \backsim 20 \mathrm{mg} / \mathrm{L} * 40 \mathrm{mg} / \mathrm{L} \_$PFO

8, c, d PFO nonlinearized model of adsorption kinetics conducted at $\mathrm{pH} 2$ and 8 . Error bars represent the standard deviation of two replicates

dosages, etc.) should be conducted to explore the exposed assertions.

Even though our linear results suggested the PFO model be discarded, the nonlinear form of the model fitted in good agreement the experimental data, as indicated by small MPSD error function (Fig. 3c, d; Table 4). In spite of erratic adsorption rate behavior, the calculated adsorption at equilibrium was found a little lower but much approximated to experimental data than that recorded with the linear model; hence, smaller Chi-square values than $\mathrm{Chi}$ square tabular values were obtained. Accordingly, the PFO nonlinear model properly predicted the equilibrium adsorption capacity for adsorption kinetics of arsenate onto magnetic iron-manganese biochar composites [57], arsenic(III/V) on nano-iron ion enrich material [58], arsenite on pine cone-magnetite composite [18], and arsenic(III/V) on magnetic $\mathrm{Fe}_{3} \mathrm{O}_{4} @ \mathrm{CuO}$ nanocomposite assembled on graphene oxide sheets [59]. Hence, the kinetics of As(III) adsorption onto ferrite NPs might be reliably described by the PFO nonlinear model. So that the pseudo-first-order 
Table 4 Kinetic parameters of the pseudo-first-order (PFO) model

\begin{tabular}{|c|c|c|c|c|c|}
\hline $\mathrm{As}(\mathrm{III}), \mathrm{pH} 2$ & $k_{1}\left(\min ^{-1}\right)$ & $R^{2}$ & $q_{\mathrm{e}, \mathrm{exp}}(\mathrm{mg} / \mathrm{g})$ & $q_{\mathrm{e}, \mathrm{cal}}(\mathrm{mg} / \mathrm{g})$ & $\chi^{2}\left(\Sigma x^{2}=348.29\right)$ \\
\hline \multicolumn{6}{|c|}{ Linear model $\ln \left(q_{\mathrm{e}}-q_{t}\right)=\ln q_{\mathrm{e}}-k_{1} t$ Eq. (3) } \\
\hline $2 \mathrm{mg} / \mathrm{L}$ & -0.0253 & 0.89 & 5.39 & 0.72 & 30.20 \\
\hline $5 \mathrm{mg} / \mathrm{L}$ & -0.0253 & 0.99 & 12.85 & 5.29 & 10.80 \\
\hline $10 \mathrm{mg} / \mathrm{L}$ & -0.0066 & 0.55 & 20.54 & 5.26 & 44.34 \\
\hline $20 \mathrm{mg} / \mathrm{L}$ & -0.0069 & 0.84 & 32.05 & 8.02 & 72.04 \\
\hline $40 \mathrm{mg} / \mathrm{L}$ & -0.0140 & 0.92 & 49.53 & 8.72 & 190.91 \\
\hline $\mathrm{As}(\mathrm{III}), \mathrm{pH} 2$ & $k_{1}\left(\min ^{-1}\right)$ & MPSD & $q_{\mathrm{e}, \exp }(\mathrm{mg} / \mathrm{g})$ & $q_{\mathrm{e}, \mathrm{cal}}(\mathrm{mg} / \mathrm{g})$ & $\chi^{2}\left(\Sigma \chi^{2}=1.1980\right)$ \\
\hline \multicolumn{6}{|c|}{ Nonlinear model $q_{t}=\left(q_{\mathrm{e}}-e^{-k_{1} t}\right)$ Eq. (4) } \\
\hline $2 \mathrm{mg} / \mathrm{L}$ & 0.2350 & 0.0056 & 5.39 & 5.29 & 0.0019 \\
\hline $5 \mathrm{mg} / \mathrm{L}$ & 0.1526 & 0.0986 & 12.85 & 11.94 & 0.0694 \\
\hline $10 \mathrm{mg} / \mathrm{L}$ & 0.2073 & 0.0732 & 20.54 & 18.14 & 0.3175 \\
\hline $20 \mathrm{mg} / \mathrm{L}$ & 0.2507 & 0.0477 & 32.05 & 28.27 & 0.5054 \\
\hline $40 \mathrm{mg} / \mathrm{L}$ & 0.4952 & 0.0217 & 49.53 & 45.80 & 0.3038 \\
\hline $\mathrm{As}(\mathrm{III}), \mathrm{pH} 8$ & $k_{1}\left(\min ^{-1}\right)$ & $R^{2}$ & $q_{\mathrm{e}, \exp }(\mathrm{mg} / \mathrm{g})$ & $q_{\mathrm{e}, \mathrm{cal}}(\mathrm{mg} / \mathrm{g})$ & $\chi^{2}\left(\Sigma \chi^{2}=46.49\right)$ \\
\hline \multicolumn{6}{|c|}{ Linear model $\ln \left(q_{e}-q_{t}\right)=\ln q_{e}-k_{1} t$ Eq. (3) } \\
\hline $2 \mathrm{mg} / \mathrm{L}$ & -0.0119 & 0.67 & 3.93 & 1.37 & 4.75 \\
\hline $5 \mathrm{mg} / \mathrm{L}$ & -0.0136 & 0.94 & 7.80 & 3.30 & 6.14 \\
\hline $10 \mathrm{mg} / \mathrm{L}$ & -0.0161 & 0.87 & 12.03 & 5.59 & 7.42 \\
\hline $20 \mathrm{mg} / \mathrm{L}$ & -0.0175 & 0.96 & 21.36 & 8.32 & 20.44 \\
\hline $40 \mathrm{mg} / \mathrm{L}$ & -0.0285 & 0.89 & 32.98 & 20.41 & 7.74 \\
\hline $\mathrm{As}(\mathrm{III}), \mathrm{pH} 8$ & $k_{1}\left(\min ^{-1}\right)$ & MPSD & $q_{\mathrm{e}, \exp }(\mathrm{mg} / \mathrm{g})$ & $q_{\mathrm{e}, \mathrm{cal}}(\mathrm{mg} / \mathrm{g})$ & $\chi^{2}\left(\Sigma \chi^{2}=0.8584\right)$ \\
\hline \multicolumn{6}{|c|}{ Nonlinear model $q_{t}=\left(q_{e}-e^{-k_{1} t}\right)$ Eq. (4) } \\
\hline $2 \mathrm{mg} / \mathrm{L}$ & 0.2000 & 0.1610 & 3.93 & 3.43 & 0.0729 \\
\hline $5 \mathrm{mg} / \mathrm{L}$ & 0.1076 & 0.2139 & 7.80 & 7.04 & 0.0820 \\
\hline $10 \mathrm{mg} / \mathrm{L}$ & 0.2077 & 0.1603 & 12.03 & 10.12 & 0.3605 \\
\hline $20 \mathrm{mg} / \mathrm{L}$ & 0.1189 & 0.1075 & 21.36 & 19.86 & 0.1133 \\
\hline 40 mg/L & 0.1082 & 0.1015 & 32.98 & 30.34 & 0.2297 \\
\hline
\end{tabular}

model should be carefully explored in its nonlinear form, before misreading discarding due to linear adjustment failure.

\subsubsection{Pseudo-second-order (PSO) model}

Although there are many factors which influence the adsorption capacity (initial adsorbate concentration, reaction temperature, $\mathrm{pH}$ of the solution, adsorbent particle size and dose, and the nature of the solute), a kinetic model is concerned only with the effect of observable parameters on the overall rate. Thus, the pseudo-secondorder (PSO) expression has been applied to sorption of several organic and inorganic substances from aqueous solutions [32]. Holding on, As(III) adsorption onto manganese ferrite NPs followed in very good agreement the pseudo-second-order kinetic model in its linear and nonlinear forms (Fig. 4; Table 5). As a general trend, for both forms of the models and the two pHs tested, the initial
PSO adsorption rate $(h)$ increased whereas the PSO constant rate $\left(k_{2}\right)$ diminished with increasing As(III) nominal concentrations. Hence, conversely to the PFO model, in the PSO model adsorption rates were found dependent on initial arsenic concentrations. Moreover, PSO constant rates $\left(k_{2}\right)$ were similar when comparing the linear and nonlinear models at the same $\mathrm{pH}$, but upper initial adsorption rates $(h)$ were recorded for the nonlinear model. High linear regression coefficients $\left(R^{2} \approx 1.0\right)$ and sharp comparison between experimental and calculated adsorption at equilibrium $\left(\Sigma \chi^{2}<0.05\right)$ suggested better fit with the linear than the nonlinear model $\left(\Sigma \chi^{2}<0.50\right)$, but being nonetheless, the two values were comparative lower than the Chisquare tabular value (9.488). Very small Chi-square test means that calculated data fitted extremely well experimental data. Thus, the PSO model fittingness was found markedly improved as compared to the PFO model.

Even though the PSO model has been advised for low initial solute concentrations [30], the kinetics of 


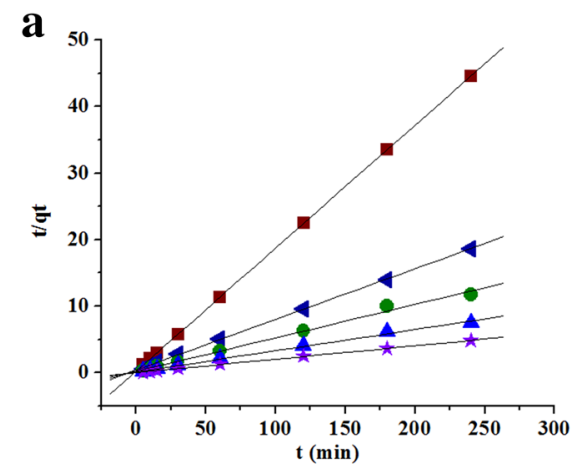

- $2 \mathrm{mg} / \mathrm{L} \ 5 \mathrm{mg} / \mathrm{L} \bullet 10 \mathrm{mg} / \mathrm{L} \Delta 20 \mathrm{mg} / \mathrm{L} \star 40 \mathrm{mg} / \mathrm{L} \_$PSO

c

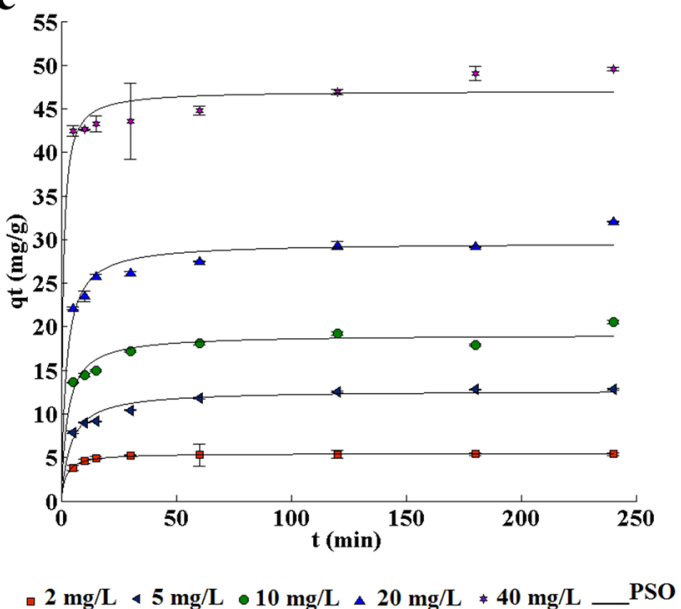

Fig. 4 Linear and nonlinear fit of the pseudo-second-order (PSO) kinetic model of As(III) adsorption onto manganese ferrite NPs $\mathbf{a}, \mathbf{b}$ PSO linearized model of adsorption kinetics conducted at $\mathrm{pH} 2$ and

arsenic adsorption onto ferrite NPs conducted in different scenarios fit exceptionally the PSO linear model with regression coefficients $R^{2} \approx 1.00$, so that this form of the model is the most broadly reported $[2,6,13-15$, $50,53]$. Nonetheless, the PSO nonlinear model has been also demonstrated to accurately describe the kinetics of arsenic adsorption on iron-based materials [18, 59, 60]. The PSO expression has been extensively used to describe chemisorption involving valency forces through the sharing or exchange of electrons between the adsorbent and adsorbate as covalent forces and ion exchange [32]. As the PSO model poses the advantage that adsorption at equilibrium and initial adsorption rate can be calculated from itself, with no need of knowing the equilibrium sorption capacity from the experiments [32]. Since more human work should be done to apply the PSO linear model, the choice of the nonlinear model is highly advised, as it is almost instantaneously solved by software.

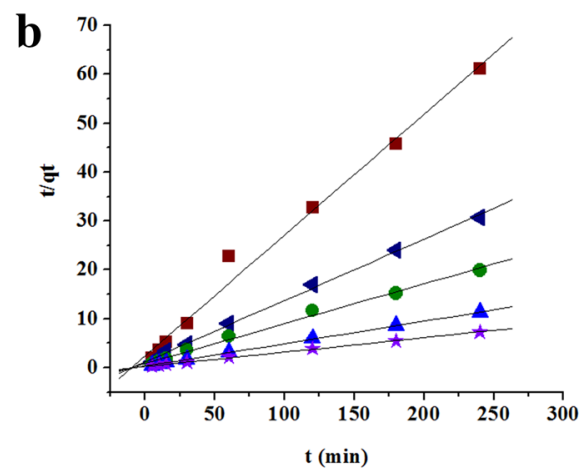

- $2 \mathrm{mg} / \mathrm{L} \ 5 \mathrm{mg} / \mathrm{L} \bullet 10 \mathrm{mg} / \mathrm{L} \triangle 20 \mathrm{mg} / \mathrm{L} \star 40 \mathrm{mg} / \mathrm{L} \_P S O$

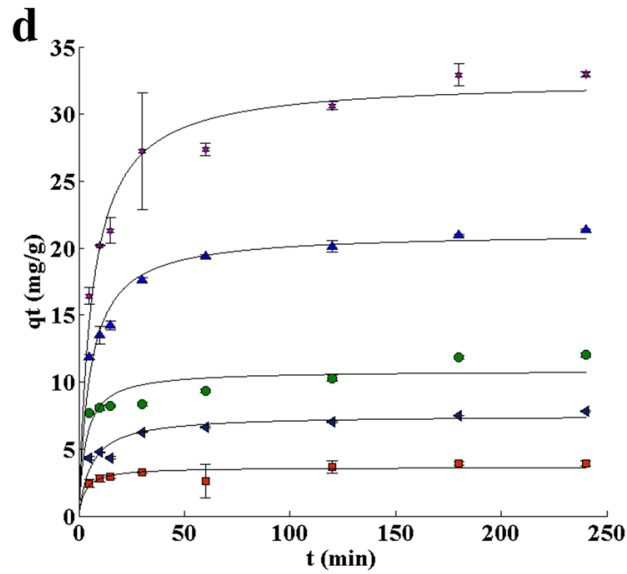

-2 mg/L $45 \mathrm{mg} / \mathrm{L} \bullet 10 \mathrm{mg} / \mathrm{L} \triangle 20 \mathrm{mg} / \mathrm{L} * 40 \mathrm{mg} / \mathrm{L} \_$PSO

8 c, d PSO nonlinearized model of adsorption kinetics conducted at $\mathrm{pH} 2$ and 8. Error bars represent the standard deviation of two replicates

\subsubsection{Elovich model}

The Elovich equation is satisfied in chemical adsorption processes and is suitable for systems with heterogeneous adsorbing surfaces, thus describing many heavy metal adsorption systems [61]. Herein, the Elovich model fitted in good agreement As(III) kinetic adsorption onto manganese ferrite NPs (Fig. 5; Table 6). In the linear model at $\mathrm{pH} 2$, initial adsorption rate $(a)$ presented erratic behavior with some very high values through increasing As(III) nominal concentrations. Nonetheless, the linear model resulted as good as the nonlinear model to predict adsorption at equilibrium, as demonstrated by the Chi-square test. In experiments conducted at $\mathrm{pH} 8$, the initial adsorption rate $(a)$ also presented an erratic behavior but displaying more moderated values than those at $\mathrm{pH} 2$. The desorption constant $(\beta)$ was similar for both forms of the Elovich model, and it was observed to decrease with arsenic nominal concentrations, as the 
Table 5 Kinetic parameters of the pseudo-second-order (PSO) model

\begin{tabular}{|c|c|c|c|c|c|c|}
\hline $\mathrm{As}(\mathrm{III}), \mathrm{pH} 2$ & $\begin{array}{l}h\left(k_{2} q_{\mathrm{e}}^{2}\right) \\
(\mathrm{mg} / \mathrm{g} \min )\end{array}$ & $k_{2}(\mathrm{~g} / \mathrm{mg} \min )$ & $R^{2}$ & $q_{\mathrm{e}, \mathrm{exp}}(\mathrm{mg} / \mathrm{g})$ & $q_{\mathrm{e}, \mathrm{cal}}(\mathrm{mg} / \mathrm{g})$ & $\chi^{2}\left(\Sigma x^{2}=0.0325\right)$ \\
\hline \multicolumn{7}{|c|}{ Linear model $\frac{t}{q_{t}}=\frac{1}{k_{2} q_{\mathrm{e}}^{2}}+\frac{1}{q_{\mathrm{e}}} t$ Eq. (5) } \\
\hline $2 \mathrm{mg} / \mathrm{L}$ & 3.41 & 0.1159 & 1.00 & 5.39 & 5.42 & 0.0002 \\
\hline $5 \mathrm{mg} / \mathrm{L}$ & 2.31 & 0.0134 & 1.00 & 12.85 & 13.15 & 0.0069 \\
\hline $10 \mathrm{mg} / \mathrm{L}$ & 3.84 & 0.0096 & 1.00 & 20.54 & 19.97 & 0.0164 \\
\hline $20 \mathrm{mg} / \mathrm{L}$ & 5.70 & 0.0057 & 1.00 & 32.05 & 31.55 & 0.0080 \\
\hline $40 \mathrm{mg} / \mathrm{L}$ & 14.79 & 0.0060 & 1.00 & 49.53 & 49.75 & 0.0010 \\
\hline $\mathrm{As}(\mathrm{III}), \mathrm{pH} 2$ & $\begin{array}{l}h\left(k_{2} q_{e}^{2}\right) \\
(\mathrm{mg} / \mathrm{g} \min )\end{array}$ & $k_{2}(\mathrm{~g} / \mathrm{mg} \min )$ & MPSD & $q_{\mathrm{e}, \exp }(\mathrm{mg} / \mathrm{g})$ & $q_{\mathrm{e}, \mathrm{cal}}(\mathrm{mg} / \mathrm{g})$ & $\chi^{2}\left(\Sigma \chi^{2}=0.4307\right)$ \\
\hline \multicolumn{7}{|c|}{ Nonlinear model $q_{t}=\frac{k_{2} q_{\mathrm{e}}^{2} t}{1+k_{2} q_{\mathrm{e}} t}$ Eq. (6) } \\
\hline $2 \mathrm{mg} / \mathrm{L}$ & 2.74 & 0.0911 & 0.0018 & 5.39 & 5.48 & 0.0006 \\
\hline $5 \mathrm{mg} / \mathrm{L}$ & 3.16 & 0.0196 & 0.0286 & 12.70 & 12.70 & 0.0000 \\
\hline $10 \mathrm{mg} / \mathrm{L}$ & 7.09 & 0.0194 & 0.0264 & 20.54 & 19.10 & 0.1086 \\
\hline $20 \mathrm{mg} / \mathrm{L}$ & 13.90 & 0.0158 & 0.0177 & 32.05 & 29.65 & 0.1943 \\
\hline $40 \mathrm{mg} / \mathrm{L}$ & 60.55 & 0.0273 & 0.0125 & 49.53 & 47.09 & 0.1264 \\
\hline $\mathrm{As}(\mathrm{III}), \mathrm{pH} 8$ & $\begin{array}{l}h\left(k_{2} q_{\mathrm{e}}^{2}\right) \\
(\mathrm{mg} / \mathrm{g} \min )\end{array}$ & $k_{2}(\mathrm{~g} / \mathrm{mg} \min )$ & $R^{2}$ & $q_{\mathrm{e}, \exp }(\mathrm{mg} / \mathrm{g})$ & $q_{\mathrm{e}, \mathrm{cal}}(\mathrm{mg} / \mathrm{g})$ & $\chi^{2}\left(\Sigma \chi^{2}=0.0490\right)$ \\
\hline \multicolumn{7}{|c|}{ Linear model $\frac{t}{q_{t}}=\frac{1}{k_{2} q_{e}^{2}}+\frac{1}{q_{e}} t$ Eq. (5) } \\
\hline $2 \mathrm{mg} / \mathrm{L}$ & 0.42 & 0.0255 & 0.99 & 3.93 & 4.04 & 0.0032 \\
\hline $5 \mathrm{mg} / \mathrm{L}$ & 0.86 & 0.0137 & 1.00 & 7.80 & 7.94 & 0.0028 \\
\hline $10 \mathrm{mg} / \mathrm{L}$ & 1.18 & 0.0078 & 1.00 & 12.03 & 12.28 & 0.0050 \\
\hline $20 \mathrm{mg} / \mathrm{L}$ & 3.18 & 0.0067 & 1.00 & 21.36 & 21.80 & 0.0089 \\
\hline $40 \mathrm{mg} / \mathrm{L}$ & 3.94 & 0.0034 & 1.00 & 32.98 & 33.97 & 0.0290 \\
\hline $\mathrm{As}(\mathrm{III}), \mathrm{pH} 8$ & $\begin{array}{l}h\left(k_{2} q_{\mathrm{e}}^{2}\right) \\
(\mathrm{mg} / \mathrm{g} \min )\end{array}$ & $k_{2}(\mathrm{~g} / \mathrm{mg} \min )$ & MPSD & $q_{\mathrm{e}, \mathrm{exp}}(\mathrm{mg} / \mathrm{g})$ & $q_{\mathrm{e}, \mathrm{cal}}(\mathrm{mg} / \mathrm{g})$ & $\chi^{2}\left(\Sigma \chi^{2}=0.1515\right)$ \\
\hline \multicolumn{7}{|c|}{ Nonlinear model $q_{t}=\frac{k_{2} q_{\mathrm{e}}^{2} t}{1+k_{2} q_{\mathrm{e}} t}$ Eq. (6) } \\
\hline $2 \mathrm{mg} / \mathrm{L}$ & 1.19 & 0.0900 & 0.1235 & 3.93 & 3.64 & 0.0210 \\
\hline $5 \mathrm{mg} / \mathrm{L}$ & 1.28 & 0.0226 & 0.1036 & 7.80 & 7.52 & 0.0097 \\
\hline $10 \mathrm{mg} / \mathrm{L}$ & 3.32 & 0.0281 & 0.0919 & 12.03 & 10.86 & 0.1143 \\
\hline $20 \mathrm{mg} / \mathrm{L}$ & 4.02 & 0.0090 & 0.0304 & 21.36 & 21.16 & 0.0018 \\
\hline $40 \mathrm{mg} / \mathrm{L}$ & 5.29 & 0.0050 & 0.0292 & 32.98 & 32.58 & 0.0047 \\
\hline
\end{tabular}

tendency of ad-species to be desorbed is higher in the systems with lower bulk concentrations [35]. The parameter $\beta$ is also related to the extent of surface coverage and chemisorption activation energy, thus assuming a heterogeneous distribution of sites whose activation energies vary with surface coverage [39]. As a general trend, cumulative Chi-square values demonstrated better fit at $\mathrm{pH} 8$ than at $\mathrm{pH} 2$ for both, linear and nonlinear models, the initial adsorption rate, desorption constant and predicted equilibrium adsorption capacity being almost identical. Thus, it seems that better Elovich fit was achieved with low adsorbed arsenic concentrations, irrespective of whether the linear or nonlinear model was actually chosen.
The linearized PSO and PFO have been the models most extensively applied to describe kinetics of arsenic adsorption onto ferrite or magnetic materials. However, profitable results were recently obtained for the PSO, PFO and the Elovich nonlinear models adjusted through the nonlinear least squares method, using the correlation coefficient $R^{2}$ $[58,59]$ or the coefficient of determination $r^{2}$ [39] as indicative of model fittingness. Additionally, the normalized standard deviation (NSD), average relative error (ARE) [58], and sum of squares (SS) [39] were used as error function to compare the model applicability of the kinetics obtained from nonlinear regressions.

Summarizing the kinetic models applied in the present work, adsorption kinetics of As(III) on manganese ferrite 


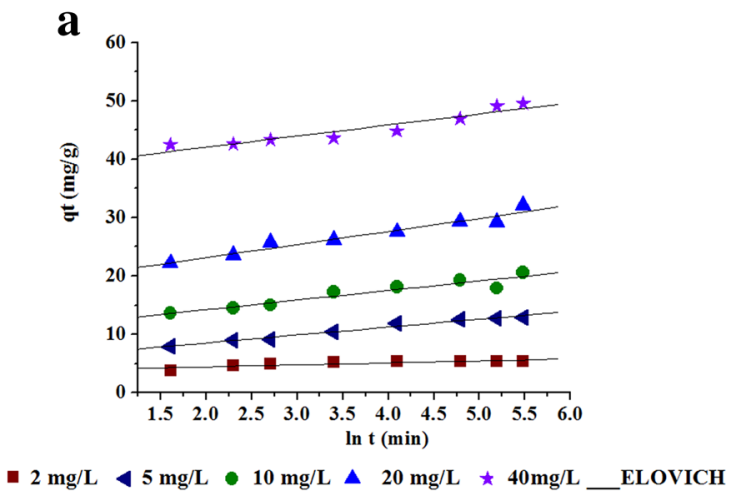

C

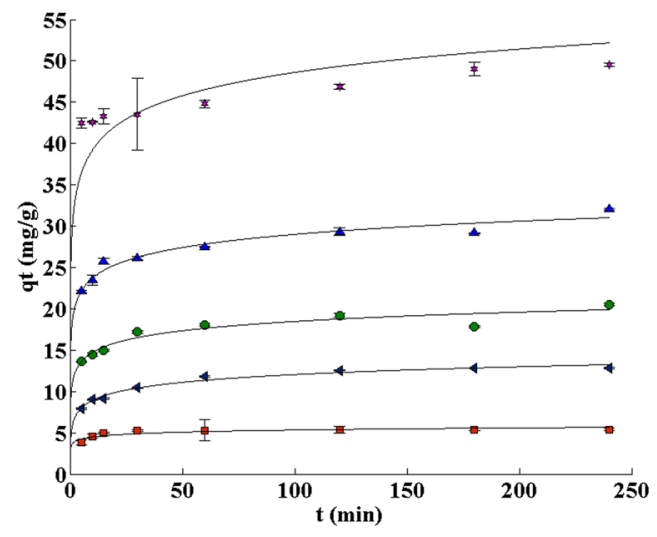

- $2 \mathrm{mg} / \mathrm{L} \& 5 \mathrm{mg} / \mathrm{L} \bullet 10 \mathrm{mg} / \mathrm{L} \leadsto 20 \mathrm{mg} / \mathrm{L} * 40 \mathrm{mg} / \mathrm{L} \_$ELOVICH

Fig. 5 Linear and nonlinear fit of the Elovich kinetic model of As(III) adsorption onto manganese ferrite NPs a, b Elovich linearized model of adsorption kinetics conducted at $\mathrm{pH} 2$ and $8 \mathbf{c}$, d Elovich

NPs were better fitted by the PSO model, followed by the Elovich model and then the PFO model. The same order of model fittingness was observed for arsenate adsorption on iron-manganese biochar composites [57] and As(III) adsorption onto nano-iron ion enrich material [58]. Conversely, among these models, the Elovich model provided the best correlation of the experimental data for $A s(V)$ adsorption on hematite-modified biochar [60] and As(III)/ $\mathrm{As}(\mathrm{V})$ adsorption on magnetic $\mathrm{Fe}_{3} \mathrm{O}_{4} @ \mathrm{CuO}$ nanocomposite assembled on graphene oxide sheets [59].

\subsection{Linear and nonlinear Freundlich and Langmuir isotherm models}

Adsorption occurs by the donor-acceptor complexation mechanism where atoms of the surface functional group donate electrons to the sorbate. The position of these functional groups on the sorbent surface determines the type of sorbate/sorbent bond and therefore decides whether the process is physisorption or chemisorption [33]. Physisorption is a nonspecific reversible process

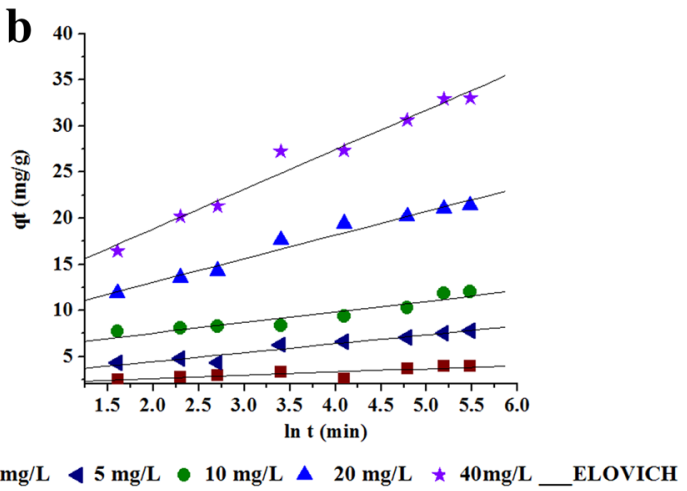

d

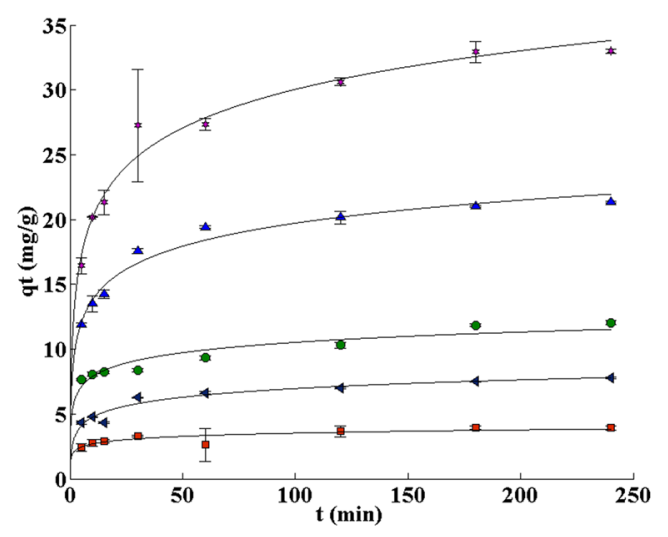

- $2 \mathrm{mg} / \mathrm{L}+5 \mathrm{mg} / \mathrm{L} \bullet 10 \mathrm{mg} / \mathrm{L} \triangle 20 \mathrm{mg} / \mathrm{L} * 40 \mathrm{mg} / \mathrm{L} \_$ELOVICH

nonlinearized model of adsorption kinetics conducted at $\mathrm{pH} 2$ and 8. Error bars represent the standard deviation of two replicates

with no electron transfer occurring, where van der Waals and physical bonds are produced, thus being indicative of a multilayer process. Chemisorption is commonly an irreversible specific process involving ionic or covalent bond formation with high energy requirement, where monolayer generation is expected [33]. Accordingly, the Freundlich isotherm can be applied to multilayer adsorption, with non-uniform distribution of adsorption heat and affinities over the heterogeneous surface; meanwhile, the Langmuir isotherm assumes monolayer adsorption of one molecule in thickness, with adsorption occurring at finite number of specific localized sites, that are identical and equivalent, with no lateral interaction and steric hindrance between the adsorbed molecules, even on adjacent sites [34].

The simplest method to solve the two parameter isotherms is to transform the equations into a linear form so that the constants can be easily calculated by applying linear regression. Thus, the Freundlich model fitted in very good agreement $\mathrm{As}$ (III) equilibrium adsorption data. The linear model (Fig. 6a; Table 7) showed well-defined 
Table 6 Kinetic parameters of the Elovich model

\begin{tabular}{|c|c|c|c|c|c|c|}
\hline $\mathrm{As}(\mathrm{III}), \mathrm{pH} 2$ & $a(\mathrm{mg} / \mathrm{g} \mathrm{min})$ & $\beta(\mathrm{g} / \mathrm{mg})$ & $R^{2}$ & $q_{\mathrm{e}, \exp }(\mathrm{mg} / \mathrm{g})$ & $q_{\mathrm{e}, \mathrm{cal}}(\mathrm{mg} / \mathrm{g})$ & $\chi^{2}\left(\sum \chi^{2}=0.0978\right)$ \\
\hline \multicolumn{7}{|c|}{ Linear model $q_{t}=\frac{1}{\beta} \ln \alpha \beta+\frac{1}{\beta} \ln t$ Eq. (7) } \\
\hline $2 \mathrm{mg} / \mathrm{L}$ & $23,851.89$ & 2.9709 & 0.76 & 5.39 & 5.60 & 0.0082 \\
\hline $5 \mathrm{mg} / \mathrm{L}$ & 95.45 & 0.7351 & 0.98 & 12.85 & 13.24 & 0.0114 \\
\hline $10 \mathrm{mg} / \mathrm{L}$ & 1377.59 & 0.6142 & 0.91 & 20.54 & 19.90 & 0.0207 \\
\hline $20 \mathrm{mg} / \mathrm{L}$ & 9427.62 & 0.4473 & 0.95 & 32.05 & 30.91 & 0.0420 \\
\hline $40 \mathrm{mg} / \mathrm{L}$ & $1,079,171,753.11$ & 0.5269 & 0.89 & 49.53 & 48.66 & 0.0155 \\
\hline $\mathrm{As}(\mathrm{III}), \mathrm{pH} 2$ & $a(\mathrm{mg} / \mathrm{g} \min )$ & $\beta(\mathrm{g} / \mathrm{mg})$ & MPSD & $q_{\mathrm{e}, \exp }(\mathrm{mg} / \mathrm{g})$ & $q_{\mathrm{e}, \mathrm{cal}}(\mathrm{mg} / \mathrm{g})$ & $\chi^{2}\left(\Sigma x^{2}=0.2102\right)$ \\
\hline \multicolumn{7}{|c|}{ Nonlinear model $q_{t}=\frac{1}{\beta} \ln (1+\alpha \beta t)$ Eq. (8) } \\
\hline $2 \mathrm{mg} / \mathrm{L}$ & 7565.30 & 2.7266 & 0.0252 & 5.39 & 5.65 & 0.0120 \\
\hline $5 \mathrm{mg} / \mathrm{L}$ & 95.05 & 0.7347 & 0.0044 & 12.85 & 13.24 & 0.0115 \\
\hline $10 \mathrm{mg} / \mathrm{L}$ & 1377.00 & 0.6142 & 0.0122 & 20.54 & 19.90 & 0.0206 \\
\hline $20 \mathrm{mg} / \mathrm{L}$ & 6824.80 & 0.4344 & 0.0048 & 32.05 & 31.03 & 0.0335 \\
\hline $40 \mathrm{mg} / \mathrm{L}$ & 6116.90 & 0.2453 & 0.0388 & 49.53 & 52.16 & 0.1326 \\
\hline $\mathrm{As}(\mathrm{III}), \mathrm{pH} 8$ & $a(\mathrm{mg} / \mathrm{g} \min )$ & $\beta(\mathrm{g} / \mathrm{mg})$ & $R^{2}$ & $q_{\mathrm{e}, \exp }(\mathrm{mg} / \mathrm{g})$ & $q_{\mathrm{e}, \text { cal }}(\mathrm{mg} / \mathrm{g})$ & $\chi^{2}\left(\sum x^{2}=0.0608\right)$ \\
\hline \multicolumn{7}{|c|}{ Linear model $q_{t}=\frac{1}{\beta} \ln \alpha \beta+\frac{1}{\beta} \ln t$ Eq. (7) } \\
\hline $2 \mathrm{mg} / \mathrm{L}$ & 63.82 & 2.7765 & 0.75 & 3.93 & 3.84 & 0.0021 \\
\hline $5 \mathrm{mg} / \mathrm{L}$ & 13.00 & 1.0350 & 0.93 & 7.80 & 7.81 & 0.0000 \\
\hline $10 \mathrm{mg} / \mathrm{L}$ & 109.57 & 0.8707 & 0.89 & 12.03 & 11.53 & 0.0219 \\
\hline $20 \mathrm{mg} / \mathrm{L}$ & 55.80 & 0.3898 & 0.97 & 21.36 & 21.96 & 0.0164 \\
\hline $40 \mathrm{mg} / \mathrm{L}$ & 46.76 & 0.2328 & 0.97 & 32.98 & 33.80 & 0.0201 \\
\hline $\mathrm{As}(\mathrm{III}), \mathrm{pH} 8$ & $a(\mathrm{mg} / \mathrm{g} \min )$ & $\beta(\mathrm{g} / \mathrm{mg})$ & MPSD & $q_{\mathrm{e}, \exp }(\mathrm{mg} / \mathrm{g})$ & $q_{\mathrm{e}, \mathrm{cal}}(\mathrm{mg} / \mathrm{g})$ & $\chi^{2}\left(\Sigma \chi^{2}=0.0607\right)$ \\
\hline \multicolumn{7}{|c|}{ Nonlinear model $q_{t}=\frac{1}{\beta} \ln (1+\alpha \beta t)$ Eq. (8) } \\
\hline $2 \mathrm{mg} / \mathrm{L}$ & 63.63 & 2.7755 & 0.0812 & 3.93 & 3.84 & 0.0020 \\
\hline $5 \mathrm{mg} / \mathrm{L}$ & 12.69 & 1.0310 & 0.0416 & 7.80 & 7.81 & 0.0000 \\
\hline $10 \mathrm{mg} / \mathrm{L}$ & 108.68 & 0.8698 & 0.0267 & 12.03 & 11.53 & 0.0219 \\
\hline $20 \mathrm{mg} / \mathrm{L}$ & 55.22 & 0.3893 & 0.0091 & 21.36 & 21.96 & 0.0167 \\
\hline $40 \mathrm{mg} / \mathrm{L}$ & 45.91 & 0.2322 & 0.0117 & 32.98 & 33.80 & 0.0201 \\
\hline
\end{tabular}

straight lines with high linear regression coefficients $\left(R^{2}=0.98-0.99\right)$ for the two $\mathrm{pHs}$ tested. Small MPSD error function values also demonstrated good fittingness of the nonlinear model (Fig. 6c; Table 7). However, at pH 2 the Chi-square test showed the linear model $\left(\Sigma \chi^{2}=2.17\right)$ to better fit adsorption at equilibrium than the nonlinear model $\left(\Sigma \chi^{2}=3.94\right)$. But at $\mathrm{pH} 8$, the nonlinear model resulted as good as the linear model, the model fittingness being improved. As the parameters of the isotherm $K_{\mathrm{F}}$ and $b_{\mathrm{F}}$ were found approximated and the Chi-square test values were smaller than the tabular Chi-square (9.488) at both $\mathrm{pHs}$, it resulted indistinct to use the linear or the nonlinear form of the Freundlich model.

The linear Langmuir model (Fig. 5b; Table 7) presented defined straight lines supported by acceptable linear regression coefficients for both $\mathrm{pHs}$ tested $\left(R^{2}=0.90-0.94\right)$. However, as most points of the graphs are overlapped inherent bias can result from linearization despite bearable linear regression coefficients. Accordingly, when using the parameters of the isotherm $\left(K_{\mathrm{L}}\right.$ and $\left.a_{\mathrm{L}}\right)$ the calculated adsorption at equilibrium resulted underestimated as compared to experimental data, recording similar values in spite of increasing As(III) nominal concentrations (data not shown). This way, in the conditions assayed (293-295 K) the Chi-square test demonstrated the unsuitability of the Langmuir model in its linear form despite acceptable $R^{2}$ values. Thus, probable misconceptions might occur if the linear regression coefficient is the unique criterion for model fittingness. In fact, linear regression coefficient values higher than 0.99 firstly suggested the Langmuir model to outstandingly fit the equilibrium adsorption of $\mathrm{Cr}(\mathrm{VI})$ and $\mathrm{Cd}(\mathrm{II})$ on citrate-coated magnetite NPs. Nonetheless, the nonlinear fitting demonstrated the Langmuir model not to properly describe such data, but it was only gotten with the Freundlich model [51].

In the present work, when using the nonlinear Langmuir model the solute adsorptivity $\left(K_{L}\right)$ and the energy of adsorption $\left(a_{\mathrm{L}}\right)$ parameters were found of much lesser 

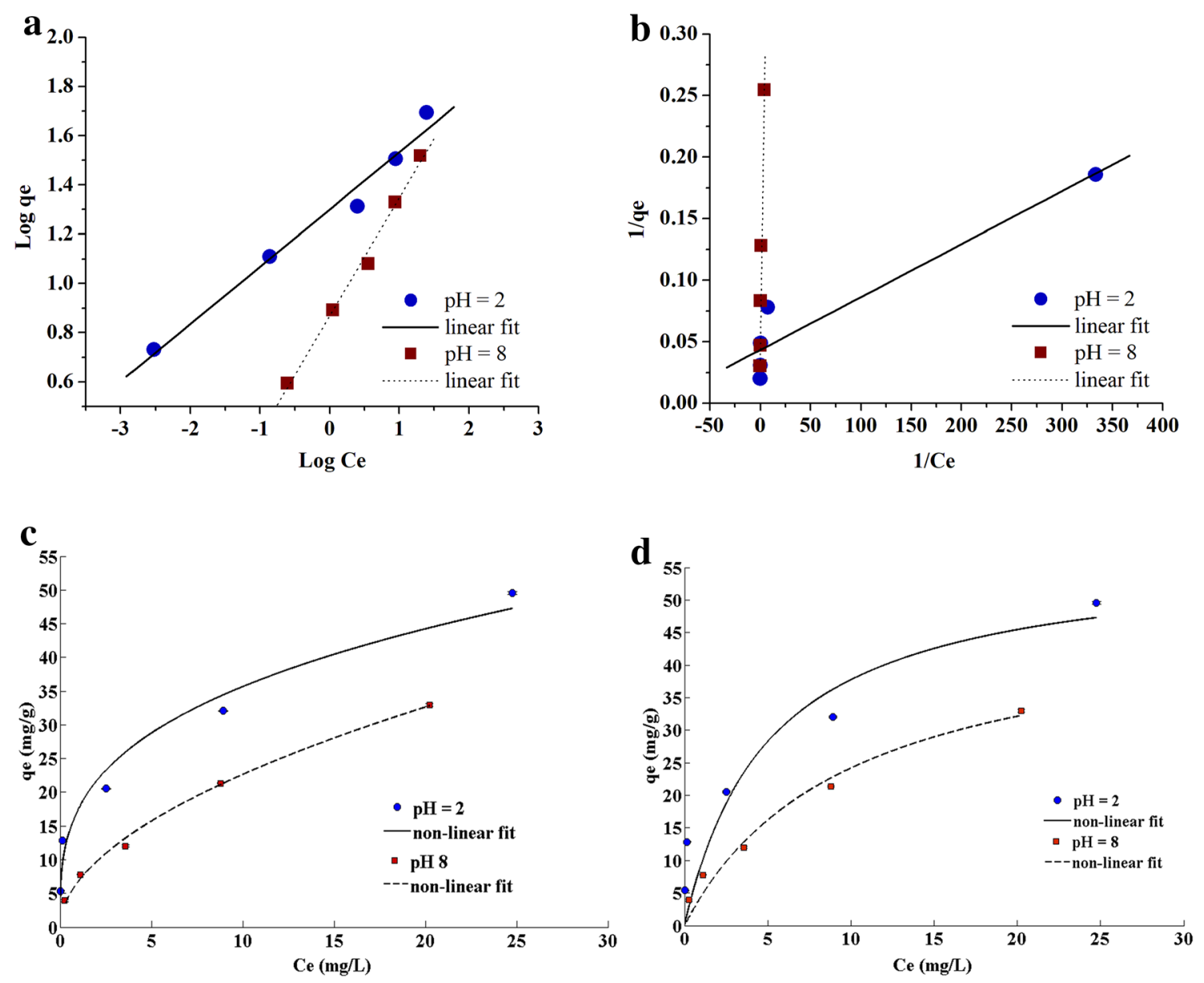

Fig. 6 Linear and nonlinear fit of Freundlich and Langmuir isotherm models of As(III) adsorption onto manganese ferrite NPs a Freundlich and $\mathbf{b}$ Langmuir linearized models $\mathbf{c}$ Freundlich and $\mathbf{d}$ Langmuir nonlinearized models, 0.40 g/L NPs dosage and $293-295 \mathrm{~K}$

Table 7 Parameters of the Freundlich and Langmuir isotherm models

\begin{tabular}{|c|c|c|c|c|c|c|c|c|}
\hline \multirow[t]{3}{*}{ Freundlich } & \multicolumn{4}{|c|}{ Linear model } & \multicolumn{4}{|c|}{ Nonlinear model } \\
\hline & \multicolumn{4}{|c|}{$\log q_{\mathrm{e}}=b_{\mathrm{F}} \log C_{\mathrm{e}}+\log K_{\mathrm{F}}$ Eq. (9) } & \multicolumn{4}{|c|}{$q_{\mathrm{e}}=K_{\mathrm{F}} C_{\mathrm{e}}^{b_{\mathrm{F}}}$ Eq. (10) } \\
\hline & $K_{\mathrm{F}}(\mathrm{L} / \mathrm{g})$ & $b_{\mathrm{F}}$ & $R^{2}$ & $\Sigma x^{2}$ & $K_{\mathrm{F}}(\mathrm{L} / \mathrm{g})$ & $b_{\mathrm{F}}$ & MPSD & $\Sigma x^{2}$ \\
\hline $\mathrm{pH} 2$ & 19.97 & 0.23 & 0.98 & 2.1709 & 17.48 & 0.31 & 0.3090 & 3.9394 \\
\hline $\mathrm{pH} 8$ & 7.37 & 0.48 & 0.99 & 0.2949 & 6.74 & 0.53 & 0.0468 & 0.3081 \\
\hline \multirow[t]{3}{*}{ Langmuir } & \multicolumn{4}{|c|}{ Linear model } & \multicolumn{4}{|c|}{ Nonlinear model } \\
\hline & \multicolumn{4}{|c|}{$\frac{1}{q_{\mathrm{e}}}=\frac{1}{K_{\mathrm{L}} C_{\mathrm{e}}}+\frac{a_{\mathrm{L}}}{K_{\mathrm{L}}} \mathrm{Eq} .(11)$} & \multicolumn{4}{|c|}{$q_{\mathrm{e}}=\frac{k_{\mathrm{L}} C_{\mathrm{e}}}{1+a_{\mathrm{L}} C_{\mathrm{e}}}$ Eq. (12) } \\
\hline & $\overline{K_{\mathrm{L}}(\mathrm{L} / \mathrm{g})}$ & $a_{\mathrm{L}}(\mathrm{L} / \mathrm{mg})$ & $R^{2}$ & $\sum x^{2}$ & $\overline{K_{\mathrm{L}}(\mathrm{L} / \mathrm{g})}$ & $a_{\mathrm{L}}(\mathrm{L} / \mathrm{mg})$ & MPSD & $\sum x^{2}$ \\
\hline $\mathrm{pH} 2$ & 2327.91 & 101.24 & 0.90 & 37.9341 & 11.18 & 0.20 & 1.7909 & 939.3557 \\
\hline $\mathrm{pH} 8$ & 19.35 & 1.03 & 0.94 & 14.8083 & 4.91 & 0.10 & 0.6323 & 8.1146 \\
\hline
\end{tabular}

$\Sigma \chi^{2}$ are the cumulative Chi-square values obtained from the comparison between $q_{\mathrm{e}, \exp }$ and $q_{\mathrm{e}, \text { cal }}$ of every As(III) nominal concentration

magnitude as contrasted to the linear model (Fig. 6d; Table 7). However, in comparison with experimental data, acute prediction of equilibrium adsorption capacity $\left(q_{\mathrm{e}}\right)$ just was achieved starting $10 \mathrm{mg} / \mathrm{L}$ As(III), while very small $q_{\mathrm{e}}$ values were obtained for lower As(III) nominal concentrations. Even so, the Chi-square test $\left(\Sigma \chi^{2}=8.11\right)$ indicated 
tolerable fittingness at $\mathrm{pH}$ 8. Although at first glance the graph could indicate some consideration for the nonlinear Langmuir model, erratic prediction of adsorption at equilibrium suggested the nonlinear model to be discarded too. Furthermore, a Freundlich-like exponential progression trend was observed in Fig. $6 \mathrm{~d}$, instead of the typical "plateau" implying monolayer adsorption. Accordingly, Freundlich isotherm gives more accurate results than the Langmuir isotherm for a wide variety of heterogeneous adsorption systems [33]. In agreement, the Freundlich model showed a strong linear relationship for As(III)/(V) adsorption on mixed magnetite-maghemite NPs [12], As(III) adsorption onto magnetite, cobalt ferrite, and manganese ferrite [15], and As(III) adsorption on nickel ferrite [17]. Conversely, better linear Langmuir model adjustment was observed for equilibrium adsorption of $\mathrm{As}(\mathrm{V})$ on magnetite, cobalt ferrite, and manganese ferrite [15]. Furthermore, the linearized Langmuir model fitted in good agreement $\mathrm{As}(\mathrm{III}) / \mathrm{As}(\mathrm{V})$ adsorption on magnetite NPs, where linear regression coefficients $\left(R^{2}\right)$ improved with increasing temperature ranging from 283 to $328 \mathrm{~K}$ [11]. Accordingly, for nonlinear models and through 298-318 K, larger correlation coefficients indicated Langmuir suitability for adsorption of different sources of arsenate on manganese ferrite NPs [2]. In contrast and in agreement with our findings, at room temperature (295-298 K) the nonlinear Freundlich model better fitted As(III) equilibrium adsorption onto manganese and cobalt ferrite NPs [45] and ultrafine hematite [13], but the nonlinear Langmuir model being slighter better than Freundlich for $\mathrm{As}(\mathrm{V})$ adsorption on hematite [13]. Improved performance of the Langmuir isotherm through increasing temperatures can be explained by the fact that chemisorption is possible over a wide temperature range, while physisorption occurs more at lower temperatures, where it is better described by the Freundlich isotherm; nonetheless, in an adsorption system both sorts are expected to occur [33]. Moreover, a re-evaluation of the Langmuir isotherm for modeling adsorption in solution was recently presented, providing further insight on adsorption and desorption processes in condensed phases [35].

As final remarks, adsorption data at equilibrium was better fitted by the Freundlich isotherm model suggesting the predominance of physisorption over the chemisorption process. This tendency could have been also strongly related to the heterogeneous adsorbent surface as suitably indicated by the Elovich kinetic model, supported by polydispersity of mean particle size revealed by NPs characterization. Additionally, in some cases, even the changes in the studied sorbate concentration range or experimental conditions can cause the isotherm fit to switch from Freundlich to Langmuir model. For instance, in similar experimental conditions but with As(III) concentrations in the range of $0.5-12 \mathrm{mg} / \mathrm{L}, \mathrm{pH} 5-9$, and suspensions of fresh cobalt ferrite NPs as adsorbent, adsorption data at equilibrium (not published yet) were properly described for both, the Freundlich and Langmuir models. Thus, with the reservation of deeper knowledge of thermodynamics of the adsorption process, in these systems both physisorption and chemisorption would be expected to occur. Accordingly, the great performance of pseudo-firstorder, pseudo-second-order, and Elovich kinetic models matched in good agreement with chemisorptions. The last reinforced by the fact that in the same experimental conditions, arsenic desorption from $\mathrm{MnFe}_{2} \mathrm{O}_{4} \mathrm{NPs}$ resulted almost negligible through increasing As(III) nominal concentrations [1]. Furthermore, it has been reported that arsenic adsorption is carried out through the replacement of the hydroxyl group of metal oxide $(\mathrm{M}-\mathrm{OH})$ with arsenate and arsenite to form monodentate, bidentate mononuclear, and bidentate binuclear complex $[15,62]$, comprising a little $\mathrm{As}(\mathrm{III})$ oxidation into $\mathrm{As}(\mathrm{V})$ during the adsorption procedure [15]. Hence, adsorption capacity of $\mathrm{MnFe}_{2} \mathrm{O}_{4}$ and $\mathrm{CoFe}_{2} \mathrm{O}_{4}$ respect to $\mathrm{Fe}_{3} \mathrm{O}_{4}$ is enhanced by the increase in surface hydroxyl groups and additionally, the decrease in the $\mathrm{pH}_{\mathrm{PZC}}$ of the adsorbent after arsenic adsorption implies the formation of negatively charged inner-sphere complexes between arsenic and adsorbent [15]. Even though chemisorptions may become a reversible process, $\mathrm{As}$ (III) can be desorbed from $\mathrm{MnFe}_{2} \mathrm{O}_{4}$ nanoadsorbents through alkali solutions [15].

\section{Conclusions}

The IPD model suggested that intraparticle diffusion was not the only rate-limiting step of As(III) adsorption onto manganese ferrite NPs, but also it was influenced by surface or film diffusion from the arsenic bulk solution to ferrite NPs. Adsorption kinetics of As(III) on manganese ferrite NPs were better described by the PSO model, followed by the Elovich model and then the PFO model. PFO rate constants were shown to be independent of As(III) initial concentrations. In contrast, the PSO initial adsorption rate increased and the PSO rate constant diminished proportionally to As(III) nominal concentrations. As(III) desorption was confidently provided by the Elovich model, while equilibrium adsorption capacity was accurately predicted by the PSO model. Only the nonlinear PFO model fitted experimental adsorption data, while the linear PSO model still better predicted adsorption at equilibrium than the nonlinear model, but both forms of the Elovich model resulted comparable. Equilibrium adsorption data were slightly better fitted by the linear than the nonlinear Freundlich isotherm model. However, the derived parameters were very similar for both isotherm models. The Chi-square 
test and the nonlinear model indicated the Langmuir isotherm to be discarded, although some consideration was formerly suggested by the linear regression coefficients. The nonlinear data fitting was shown to be very useful to solve nonlinear adsorption models through the Matlab Isqcurvefit function. This method is not restricted for two parameters models and owns the additional advantage that bias from the derived parameters is avoided, as normalization of different errors is no longer required. Any drawback might be the fact that sqcurvefit is a userdefined function; however, it can be worthily afforded.

Funding This work was funded by SEP-DGESPA-PROMEP 11095 UNSIJ-CA-3 and SEP-CONACYT CB-2012-01-181592.

\section{Compliance with ethical standards}

Conflict of interest The authors declare that they have no conflict of interest.

\section{References}

1. Martinez-Vargas S, Martínez Al, Hernández-Beteta EE, MijangosRicardez OF, Vázquez-Hipólito V, Patiño-Carachure C, LópezLuna J (2018) As(III) and As(V) adsorption on manganese ferrite nanoparticles. J Mol Struct 1154:524-534. https://doi. org/10.1016/j.molstruc.2017.10.076

2. Hu Q, Liu Y, Gu X, Zhao Y (2017) Adsorption behavior and mechanism of different arsenic species on mesoporous $\mathrm{MnFe}_{2} \mathrm{O}_{4}$ magnetic nanoparticles. Chemosphere 181:328-336. https://doi. org/10.1016/j.chemosphere.2017.04.049

3. Ghosh G, Mukhopadhyay DK (2019) Human health hazards due to arsenic and fluoride contamination in drinking water and food chain. In: Sikdar PK (ed) Groundwater development and management: issues and challenges in South Asia. Springer, Berlin. https://doi.org/10.1007/978-3-319-75115-3_15

4. O'Day PA (2006) Chemistry and mineralogy of arsenic. Elements 2:77-83. https://doi.org/10.2113/gselements.2.2.77

5. Zaccone C, Lobianco D, Raber G, D'Orazio V, Shotyk W, Miano TM, Francesconi K (2018) Methylated arsenic species throughout a 4-m deep core from a free-floating peat island. Sci Total Environ 621:67-74. https://doi.org/10.1016/j.scitotenv.2017.11.152

6. Rashid M, Sterbinsky GE, Pinilla MÁG, Cai Y, O'Shea KE (2018) Kinetic and mechanistic evaluation of inorganic arsenic species adsorption onto humic acid grafted magnetite nanoparticles. J Phys Chem C 122:13540-13547. https://doi.org/10.1021/acs. jpcc.7b12438

7. Siddiqui SI, Chaudhry SA (2018) A review on graphene oxide and its composites preparation and their use for the removal of $\mathrm{As}^{3+}$ and $\mathrm{As}^{5+}$ from water under the effect of various parameters: application of isotherm, kinetic and thermodynamics. Process Saf Environ Prot 119:138-163. https://doi.org/10.1016/j. psep.2018.07.020

8. Simeonidis K, Gkinis T, Tresintsi S, Martinez-Boubeta C, Vourlias G, Tsiaoussis I, Stavropoulos G, Mitrakas M, Angelakeris M (2011) Magnetic separation of hematite-coated $\mathrm{Fe}_{3} \mathrm{O}_{4}$ particles used as arsenic adsorbents. Chem Eng J 168:1008-1015. https://doi. org/10.1016/j.cej.2011.01.074
9. Yean S, Cong L, Yavuz CT, Mayo JT, Yu WW, Kan AT, Colvin VL, Tomson MB (2005) Effect of magnetite particle size on adsorption and desorption of arsenite and arsenate. J Mater Res 20:3255-3264. https://doi.org/10.1557/jmr.2005.0403

10. Petrova TM, Fachikov L, Hristov J (2011) The magnetite as adsorbent for some hazardous species from aqueous solutions: a review. Int Rev Chem Eng 3:134-152

11. Liu CH, Chuang YH, Chen TY, Tian Y, Li H, Wang MK, Zhang W (2015) Mechanism of arsenic adsorption on magnetite nanoparticles from water: thermodynamic and spectroscopic studies. Environ Sci Technol 49:7726-7734. https://doi.org/10.1021/acs. est.5b00381

12. Chowdhury SR, Yanful EK (2010) Arsenic and chromium removal by mixed magnetite-maghemite nanoparticles and the effect of phosphate on removal. J Environ Manag 91:2238-2247. https:// doi.org/10.1016/j.jenvman.2010.06.003

13. Tang W, Li Q, Gao S, Shang JK (2011) Arsenic (III, V) removal from aqueous solution by ultrafine $\mathrm{a}-\mathrm{Fe} 2 \mathrm{O} 3$ nanoparticles synthesized from solvent thermal method. J Hazard Mater 192:131138. https://doi.org/10.1016/j.jhazmat.2011.04.111

14. Dickson D, Liu G, Cai Y (2017) Adsorption kinetics and isotherms of arsenite and arsenate on hematite nanoparticles and aggregates. J Environ Manag 186:261-267. https://doi.org/10.1016/j. jenvman.2016.07.068

15. Zhang S, Niu H, Cai Y, Zhao X, Shi Y (2010) Arsenite and arsenate adsorption on coprecipitated bimetal oxide magnetic nanomaterials: $\mathrm{MnFe}_{2} \mathrm{O}_{4}$ and $\mathrm{CoFe}_{2} \mathrm{O}_{4}$. Chem Eng J 158:599-607. https ://doi.org/10.1016/j.cej.2010.02.013

16. Martinez-Vargas S, Martínez Al, Hernández-Beteta EE, MijangosRicardez OF, Vázquez-Hipólito V, Patiño-Carachure C, Hernandez-Flores H, López-Luna J (2017) Arsenic adsorption on cobalt and manganese ferrite nanoparticles. J Mater Sci 52:6205-6215. https://doi.org/10.1007/s10853-017-0852-9

17. Karcioğlu Karakaş Z, Boncukcuoğlu R, Karakaş iH (2017) Adsorptive properties of $\mathrm{As}$ (III) from aqueous solution using magnetic nickel ferrite $\left(\mathrm{NiFe}_{2} \mathrm{O}_{4}\right)$ nanoparticles: isotherm and kinetic studies. Sep Sci Technol 52:21-34. https://doi.org/10.1080/01496 395.2016.1240693

18. Ouma ILA, Naidoo EB, Ofomaja AE (2018) Thermodynamic kinetic and spectroscopic investigation of arsenite adsorption mechanism on pine cone-magnetite composite. J Environ Chem Eng 6:5409-5419. https://doi.org/10.1016/j.jece.2018.08.035

19. Warner CL, Chouyyok W, Mackie KE, Neiner D, Saraf LV, Droubay TC, Warner MG, Addleman RS (2012) Manganese doping of magnetic iron oxide nanoparticles: tailoring surface reactivity for a regenerable heavy metal sorbent. Langmuir 28:3931-3937. https://doi.org/10.1021/la2042235

20. Siddiqui SI, Chaudhry SA (2017) Iron oxide and its modified forms as an adsorbent for arsenic removal: a comprehensive recent advancement. Process Saf Environ Prot 111:592-626. https://doi.org/10.1016/j.psep.2017.08.009

21. Lingamdinne PL, Reddy J, Rao R (2019) A comprehensive review of applications of magnetic graphene oxide based nanocomposites for sustainable water purification. J Environ Manag 231:622-634. https://doi.org/10.1016/j.jenvman.2018.10.063

22. Maiti A, Mishra S, Chaudhary M (2019) Chapter 25-nanoscale materials for arsenic removal from water. In: Thomas S, Pasquini D, Leu SY, Gopakumar AD (eds) Micro and nano technologies, nanoscale materials in water purification. Elsevier Inc., Amsterdam, pp 707-733. https://doi.org/10.1016/B978-0-12-81392 6-4.00032-X, ISBN 9780128139264

23. Nizamuddin S, Siddiqui MTH, Mubarak NM, Baloch HA, Abdullah EC, Mazari SA, Griffin GJ, Srinivasan MP, Tanksale A (2019) Chapter 17-iron oxide nanomaterials for the removal of heavy metals and dyes from wastewater. In: Thomas S, Pasquini D, Leu SY, Gopakumar AD (eds) Micro and nano technologies, nanoscale 
materials in water purification. Elsevier Inc., Amsterdam, pp 447-472. https://doi.org/10.1016/B978-0-12-813926-4.00023 -9 , ISBN 9780128139264

24. Siddiqui SI, Naushad M, Chaudhry SA (2019) Promising prospects of nanomaterials for arsenic water remediation: a comprehensive review. Process Saf Environ Prot 126:60-97. https:// doi.org/10.1016/j.psep.2019.03.037

25. Parsons JG, Lopez ML, Peralta-Videa JR, Gardea-Torresdey JL (2009) Determination of arsenic(III) and arsenic(V) binding to microwave assisted hydrothermal synthetically prepared $\mathrm{Fe}_{3} \mathrm{O}_{4}$ $\mathrm{Mn}_{3} \mathrm{O}_{4}$, and $\mathrm{MnFe}_{2} \mathrm{O}_{4}$ nanoadsorbents. Microchem J 91:100-106. https://doi.org/10.1016/j.microc.2008.08.012

26. Ho YS, McKay G (1998) A comparison of chemisorption kinetic models applied to pollutant removal on various sorbents. Process Saf Environ Prot 76:332-340. https://doi.org/10.1205/09575 8298529696

27. Weber WJ, Morris JC (1963) Kinetics of adsorption on carbon from solution. J Sanit Eng Div 89(2):31-60

28. Wu FC, Tseng RL, Juang RS (2009) Initial behavior of intraparticle diffusion model used in the description of adsorption kinetics. Chem Eng J 153:1-8. https://doi.org/10.1016/j.cej.2009.04.042

29. Ho YS, McKay G (1999) Batch lead(II) removal from aqueous solution by peat: equilibrium and kinetics. Process Saf Environ Prot 77:165-173. https://doi.org/10.1205/095758299529983

30. Azizian S (2004) Kinetic models of sorption: a theoretical analysis. J Colloid Interface Sci 276:47-52. https://doi.org/10.1016/j. jcis.2004.03.048

31. Ho YS (2004) Citation review of Lagergren kinetic rate equation on adsorption reactions. Scientometrics 59:171-177. https://doi. org/10.1023/B:SCIE.0000013305.99473.cf

32. Ho YS (2006) Review of second-order models for adsorption systems. J Hazard Mater 136:681-689. https://doi.org/10.1016/j. jhazmat.2005.12.043

33. McKay G (1996) Use of adsorbents for the removal of pollutants from wastewaters, 1st edn. CRC Press, Boca Raton

34. Foo KY, Hameed BH (2010) Insights into the modeling of adsorption isotherm systems. Chem Eng J 156:2-10. https://doi. org/10.1016/j.cej.2009.09.013

35. Azizian S, Eris S, Wilson LD (2018) Re-evaluation of the centuryold Langmuir isotherm for modeling adsorption phenomena in solution. Chem Phys 513:99-104. https://doi.org/10.1016/j. chemphys.2018.06.022

36. Ho YS, Porter JF, McKay G (2002) Equilibrium isotherm studies for the sorption of divalent metal ions onto peat: copper, nickel and lead single component systems. Water Air Soil Pollut 141:1-33. https://doi.org/10.1023/A:1021304828010

37. Guo L, Li G, Liu J, Meng Y, Xing G (2012) Nonlinear analysis of the kinetics and equilibrium for adsorptive removal of $\mathrm{Cd}(\mathrm{II})$ by starch phosphate. J Dispers Sci Technol 33:403-409. https://doi. org/10.1080/01932691.2011.567179

38. Lin J, Wang L (2009) Comparison between linear and non-linear forms of pseudo-first-order and pseudo-second-order adsorption kinetic models for the removal of methylene blue by activated carbon. Front Environ Sci Eng China 3:320-324. https:// doi.org/10.1007/s11783-009-0030-7

39. Pintor AMA, Vieira BRC, Santos SCR, Boaventura RAR, Botelho CMS (2018) Arsenate and arsenite adsorption onto iron-coated cork granulates. Sci Total Environ 642:1075-1089. https://doi. org/10.1016/j.scitotenv.2018.06.170

40. Can M (2015) Studies of the kinetics for rhodium adsorption onto gallic acid derived polymer: the application of nonlinear regression analysis. Acta Phys Pol A 127:1308-1310. https://doi. org/10.12693/APhysPolA.127.1308

41. Massart R (1981) Preparation of aqueous magnetic liquids in alkaline and acidic media. IEEE Trans Magn 17:1247-1248. https ://doi.org/10.1109/TMAG.1981.1061188
42. Boparai HK, Joseph M, O'Carroll DM (2011) Kinetics and thermodynamics of cadmium ion removal by adsorption onto nano zerovalent iron particles. J Hazard Mater 186:458-465. https:// doi.org/10.1016/j.jhazmat.2010.11.029

43. Chien SH, Clayton WR (1980) Application of Elovich equation to the kinetics of phosphate release and sorption in soils. Soil Sci Soc Am J 44:265-268. https://doi.org/10.2136/sssaj1980.03615 $995004400020013 x$

44. Ho YS, McKay G (2002) Application of kinetic models to the sorption of copper(II) on to peat. Adsorpt Sci Technol 20:797-815. https://doi.org/10.1260/026361702321104282

45. Martinez-Vargas S, Martínez Al, Hernández-Beteta EE, MijangosRicardez OF, Vázquez-Hipólito V, Patiño-Carachure C, Hernandez-Flores H, López-Luna J (2017) Arsenic adsorption on cobalt and manganese ferrite nanoparticles. J Mater Sci 52(11):62056215. https://doi.org/10.1007/s10853-017-0852-9

46. Nguyen TV, Loganathan P, Vigneswaran S, Pham N (2016) Arsenic waste from water treatment systems: characteristics, treatments and its disposal. Water Sci Technol Water Supply 14(6):939-950. https://doi.org/10.2166/ws.2014.073

47. Sarkar S, Blaney LEEM (2008) Arsenic removal from groundwater and its safe containment in a rural environment: validation of a sustainable approach. Environ Sci Technol 42:4268-4273. https ://doi.org/10.1021/es702556t

48. Nadeem M, Mahmood A, Shahid SA, Shah SS, Khalid AM, McKay $G$ (2006) Sorption of lead from aqueous solution by chemically modified carbon adsorbents. J Hazard Mater 138:604-613. https ://doi.org/10.1016/j.jhazmat.2006.05.098

49. Dey A, Singh R, Purkait MK (2014) Cobalt ferrite nanoparticles aggregated schwertmannite: a novel adsorbent for the efficient removal of arsenic. J Water Process Eng 3:1-9. https://doi. org/10.1016/j.jwpe.2014.07.002

50. Tu YJ, You CF, Chang CK, Wang SL, Chan TS (2012) Arsenate adsorption from water using a novel fabricated copper ferrite. Chem Eng J 198-199:440-448. https://doi.org/10.1016/j. cej.2012.06.006

51. Silva-Silva MJ, Mijangos-Ricardez OF, Vázquez-Hipólito V, Martinez-Vargas S, López-Luna J (2014) Single and mixed adsorption of $\mathrm{Cd}(\mathrm{II})$ and $\mathrm{Cr}(\mathrm{VI})$ onto citrate-coated magnetite nanoparticles. Desalin Water Treat 57:4008-4017. https://doi. org/10.1080/19443994.2014.991756

52. Malana MA, Qureshi RB, Ashiq MN (2011) Adsorption studies of arsenic on nano aluminium doped manganese copper ferrite polymer (MA, VA, AA) composite: kinetics and mechanism. Chem Eng J 172:721-727. https://doi.org/10.1016/j. cej.2011.06.041

53. Srivastava V, Sharma YC, Sillanpää M (2015) Application of nanomagnesso ferrite $\left(\mathrm{n}-\mathrm{MgFe}_{2} \mathrm{O}_{4}\right)$ for the removal of $\mathrm{Co}^{2+}$ ions from synthetic wastewater: kinetic, equilibrium and thermodynamic studies. Appl Surf Sci 338:42-54. https://doi.org/10.1016/j.apsus c.2015.02.072

54. Boyd GE, Schubert J, Adamson AW (1947) The exchange adsorption of ions from aqueous solutions by organic zeolites. Ionexchange equilibria. J Am Chem Soc 69:2836-2848. https://doi. org/10.1021/ja01203a064

55. Singh DB, Prasad G, Rupainwar DC, Singh VN (1988) As(III) removal from aqueous solution by adsorption. Water Air Soil Pollut 42:373-386. https://doi.org/10.1007/BF00279281

56. Singh DB, Prasad G, Rupainwar DC (1996) Adsorption technique for the treatment of $\mathrm{As}(\mathrm{V})$-rich effluents. Colloids Surf A Physicochem Eng Asp 111:49-56. https://doi.org/10.1016/09277757(95)03468-4

57. Wang S, Gao B, Li Y, Wan Y, Creamer AE (2015) Sorption of arsenate onto magnetic iron-manganese (Fe-Mn) biochar composites. RSC Adv 5:67971-67978. https://doi.org/10.1039/c5ra1 2137j 
58. Asmel NK, Yusoff ARM, Sivarama Krishna L, Majid ZA, Salmiati $S$ (2017) High concentration arsenic removal from aqueous solution using nano-iron ion enrich material (NIIEM) super adsorbent. Chem Eng J 317:343-355. https://doi.org/10.1016/j. cej.2017.02.039

59. Wu K, Jing C, Zhang J, Liu T, Yang S, Wang W (2019) Magnetic $\mathrm{Fe}_{3} \mathrm{O}_{4} @ \mathrm{CuO}$ nanocomposite assembled on graphene oxide sheets for the enhanced removal of arsenic(III/V) from water. Appl Surf Sci 466:746-756. https://doi.org/10.1016/j.apsus c.2018.10.091

60. Wang S, Gao B, Zimmerman AR, Li Y, Ma L, Harris WG, Migliaccio KW (2015) Removal of arsenic by magnetic biochar prepared from pinewood and natural hematite. Bioresour Technol 175:391-395. https://doi.org/10.1016/j.biortech.2014.10.104
61. Wu FC, Tseng RL, Juang RS (2009) Characteristics of Elovich equation used for the analysis of adsorption kinetics in dyechitosan systems. Chem Eng J 150:366-373. https://doi. org/10.1016/j.cej.2009.01.014

62. Zhang YU, Yang MIN, Dou X (2005) Arsenate adsorption on an Fe-Ce bimetal oxide adsorbent: role of surface properties. Environ Sci Technol 39:7246-7253. https://doi.org/10.1021/es050 $775 d$

Publisher's Note Springer Nature remains neutral with regard to jurisdictional claims in published maps and institutional affiliations. 